\title{
Price indexes, inequality, and the measurement of world poverty
}

\author{
Angus Deaton, Princeton University
}

January $10^{\text {th }}, 2010$

\begin{abstract}
I discuss the statistical basis for measures of world poverty and inequality, with particular attention to the role of purchasing power parity price indexes from the International Comparison Project. Global inequality increased sharply with the latest revision of the ICP, but the recent large increase in global poverty came from an inappropriate updating of the global line, not from the ICP revision. ICP comparisons between widely different countries rest on weak empirical and theoretical foundations. I argue for greater use of self-reports in international monitoring surveys, and for a global poverty line that is denominated in US dollars.
\end{abstract}

Presidential Address, American Economic Association, Atlanta, January 2010. I am grateful to Olivier Dupriez, Alan Heston and Sam Schulhofer-Wohl who have collaborated with me on related work, to them and to Erwin Diewert, Yuri Dikhanov, D. S. Prasada-Rao, and Fred Vogel who have over the years taught me about international price comparisons, as well as the Development Economics Data Group at the World Bank for supplying me with data and for their patience and help with my questions. I also thank Tony Atkinson, Tim Besley, Branko Milanovic, François Bourguignon, Anne Case, Olivier Dupriez, Bill Easterly, Alan Heston and Martin Ravallion for comments on partial drafts. The views expressed here are my own. 
This lecture is about counting the number of poor people in the world. If we ask people whether they consider themselves to be poor, or how much money someone would need to get by in their community, they appear to have little difficulty in replying. Beyond the local level, many countries, including the United States, regularly publish national counts of the number of people in poverty, and while these numbers and the procedures for calculating them are contested and debated, the estimates typically carry sufficient legitimacy to support policy, see Connie Citro and Robert Michael (1995) for the history in the US, and Rebecca Blank and Mark Greenburg (2008) for a recent proposal for reform. But once we try to calculate the number of poor people in the world, matters are more complicated. The World Bank's global poverty count, which started with Montek Ahluwalia, Nicholas Carter and Hollis Chenery (1979), and which became the dollar-a-day count in the World Development Report 1990, was incorporated into international policymaking and discussion via the Millennium Development Goals (MDGs) — the first of which is to "halve, between 1990 and 2015, the proportion of people whose income is less than $\$ 1$ a day.” This global count has an apparent transparency that helps account for its rhetorical success: it is simply the number of people in the world who live on less than a dollar a day, with the relevant dollar adjusted for international differences in prices. But this transparency and simplicity is more apparent than real. There are many complexities beneath the surface, and these are the subject matter of this paper, particularly the calculation of the global line and the adjustment for international differences in prices using purchasing power parity exchange rates. Price adjustment is also important for other purposes, such as the construction of databases such as the Penn World Table, which underpins almost all of economists' empirical understanding of the process of economic 
growth, as well as for the measurement of global income inequality, which is another of my main concerns here.

One goal of this paper is to understand why almost half a billion people were moved into poverty at the time of the revision of the purchasing power parity exchange rates in the 2005 round of the International Comparison Project (ICP). This same revision also increased global income inequality, widening the apparent distance between poor and rich countries. I shall argue that the increase in poverty had little to do with the ICP, and much to do with an inappropriate increase in the global poverty line. The causes of the increase in inequality are harder to pinpoint, but my investigations lead to skepticism about our ability to make precise comparisons of living standards between widely different countries, for example between poor countries in Africa and rich countries in the OECD.

In spite of the attention that they receive, global poverty and inequality measures are arguably of limited interest. Within nations, the procedures for calculating poverty are routinely debated by the public, the press, legislators, academics, and expert committees, and this democratic discussion legitimizes the use of the counts in support of programs of transfers and redistribution. Between nations where there is no supranational authority, poverty counts have no direct redistributive role, and there is little democratic debate by citizens, with discussion largely left to international organizations such as the United Nations and the World Bank, and to non-governmental organizations that focus on international poverty. These organizations regularly use the global counts as arguments for foreign aid and for their own activities, and the data have often been effective in mobilizing giving for poverty alleviation. They may also influence the global strategy of the World Bank, emphasizing some regions or countries as the expense of others. It is less clear that the counts 
have any direct relevance for those included in them, given that national policymaking and the country operations of the World Bank depend on local, not global poverty measures. Global poverty and global inequality measures have a central place in a cosmopolitan vision of the world, in which international organizations such as the UN and the World Bank are somehow supposed to fulfill the redistributive role of the missing global government, see for example Thomas Pogge (2002) or Peter Singer (2002). For those who do not accept the cosmopolitan vision as morally compelling or descriptively accurate, such measures are less relevant, John Rawls (1999), Thomas Nagel (2005), Leif Wenar (2006).

The paper is organized as follows. Section I explains how the dollar a day poverty numbers are calculated and how they depend on purchasing power parity exchange rates. It shows that poverty measures are sensitive to the PPPs used in their construction, and establishes the basic facts and puzzles to be addressed, particularly the increases in poverty and inequality associated with the latest ICP revisions. Sections II and III are more technical and can be skipped without losing the thread of the main argument. Section II discusses the components of the construction of PPPs that are particularly important for measuring world poverty and inequality, while Section III discusses how PPP indexes need to be reweighted for use in poverty measurement. It argues, by reference to my related work with Olivier Dupriez (2009), that the reweighting, although a clear conceptual improvement, matters less than might be thought. Section IV returns to the main argument and is concerned with the definition of the global poverty line, and I discuss ways of constructing the line based on the international price indexes and the national poverty lines of poor countries. As is always the case with poverty lines, how the poverty line is updated with respect to new information deserves as much or more attention than how its original value is set. I argue that the updating 
procedure in current use is incorrect, that it can result in reductions in national poverty causing increases in global poverty, and that this explains why the global poverty counts increased so much in the latest revision. Paradoxically, one of the main reasons that India (and the rest of the world) became poorer was because India had grown too rich. I argue for a definition of the line, and an updating method, that is substantially different from those currently in use, and that preserves a better continuity with previous estimates.

Section $\mathrm{V}$, which is again somewhat more technical, is an enquiry into the international price indexes themselves, with a focus on the factors that affect global inequality. It starts from the question of how to price comparable goods in different countries and whether the ever more precise specification of goods by the ICP has had the effect of making poor countries poorer relative to rich countries, widening our estimates of international inequality, and causing the global poverty line to increase in dollar terms at a rate that is markedly slower than the rate of inflation in the US. More generally, I discuss the special difficulties of making comparisons between countries whose relative prices and patterns of consumption are very different, for example between Japan and Kenya, or Britain and Cameroon. Such comparisons are required if we are to make multilateral price index numbers for the world as a whole, and I use data from the 2005 ICP to investigate their credibility. My analysis shows that these comparisons rest on weak theoretical foundations and are fragile in practice.

Section VI returns to the main argument and looks briefly at an alternative monitoring system based on asking people about their lives are going; I use data from the Gallup World Poll which collects an annual sample of all the people of the world. Section VII concludes, and speculates on the global system of income and poverty statistics as a whole. I argue that we should be less ambitious and more skeptical in using the international data, particularly 
when comparing poor and rich countries. I also make recommendations for improvements in the way the poverty counts are calculated, for example by bringing closer together the rhetoric and the reality of the dollar a day poverty line. I also argue that while changes in the poverty line affect the levels of global poverty more than they affect its rate of change, the levels are themselves important for the international debate.

\section{Global poverty and global inequality}

Many countries have their own national poverty lines and poverty headcounts. One candidate for an international count would use those national numbers, and add them up over all countries. The 2008 annual poverty line in the United States was $\$ 21,834$ for a family of two adults and two children, or \$14.96 per person per day; 13.2 percent of Americans live below this line. India in 2004-05 had two poverty lines, one for rural households of 11.71 rupees per person per day, and one for urban households of 17.71 rupees; at the 2005 PPP exchange rates, these lines are $\$ 0.80$ and $\$ 1.21$ per person per day (about a third of that at market exchange rates), and 27.5 percent of the Indian population lives below them. If we take the view that poverty is relative to prevailing living standards in the society in which people live, these headcount ratios might be taken to be comparable. Yet the global poverty counts aim to measure absolute poverty, and to count those who are destitute by a common global standard which might be supposed to include all of the locally poor Indians, and none of the locally

poor Americans. By this view, we might take one or the other Indian lines, and use PPP exchange rates to convert it to other currencies, and then sum the total number of people in the world who live on less than the local purchasing power equivalent of the Indian line. The pioneering paper by Ahluwalia, Carter, and Chenery (1979) used a global line based on the 
Indian poverty line, but since World Bank (1990) the global line has been an average of the international dollar value of local lines of a number of poor countries. Exactly which average is a matter of some importance, as is whether the average is better than the original Indian only line, and I shall return to both issues.

Table 1 presents the key numbers. The first three columns, taken from the World Bank’s (2008b) poverty supplement to the World Development Indicators, show the latest estimates for 1981 (which is as far back as these estimates go), 1993, and 2005. These are based on the latest version of the “dollar-a-day” global poverty line, which is $\$ 1.25$ per person per day in 2005 international dollars, and show the well-known reduction in the global headcount ratio, from 51.9 percent of the world's population in 1981 to 25.2 percent in 2005. In spite of growth in the world's population, the number of people in this kind of poverty has fallen by more than half a billion in the last quarter century. Much of this success comes from China, in the East Asia and Pacific region. The headcount ratio in sub-Saharan Africa has fallen only slowly, and there are 176 million more Africans in poverty in 2005 than was the case in 1981. South Asia, dominated by India, is part success and part failure, and the Bank—and the government of India — estimate that, in spite of a falling headcount ratio, there has been a small increase in the numbers of Indians in poverty since 1981, in spite of India’s relatively rapid growth in per capita GDP in recent years, and its relatively slow rate of population growth. The overall improvement in global poverty and the broad regional structure of that improvement show up in all versions of the counts. Even so, it is worth noting that these counts are based entirely on household survey data, and that there are often major discrepancies in growth rates between the survey data and the national accounts so that the counts in Table 1 may understate the rate of poverty reduction, see Deaton (2005). 
The last three columns in Table 1 look at three different sets of headcount ratios for 1993. The International Comparison Program has updated its estimates of PPP exchange rates on an irregular basis, with each round a substantial improvement on the previous one; the last three benchmarking exercises were in 1985, 1993, and 2005 with a particularly marked increase in consistency and coverage between the last two. The World Bank uses these estimates to update its global poverty line-defined as the average PPP poverty line for a group of the world's poorest countries - and to revise the conversions of that line into local currencies. The original poverty line of \$1.01 in 1985 PPP (\$370 per year, in World Bank, 1990, Figure 2.1 and Table 2.1) rose to \$1.08 in 1993 international dollars, and to \$1.25 in 2005 international dollars. (By contrast, the US CPI rose by 34 percent from 1985 to 1993 and a further 35 percent from 1993 to 2005.) The revision from 1985 to 1993 had relatively little effect on the global count, but made sub-Saharan Africa appear to be much poorer, and Latin America appear to be much less poor. Indeed, it is the 1993 revision that “established” sub-Saharan Africa as the region with the highest headcount ratio, a fact that has dominated subsequent discussions of world poverty; prior to revision, the measured prevalence of poverty in South Asia was substantially higher than in sub-Saharan Africa. At the time of that revision, I commented that "changes of this size risk swamping real changes, and it seems impossible to make statements about changes in world poverty when the ground underneath one's feet is changing in this way,” Deaton (2001). The 2005 revision shifts the ground even more. The global count for 1993 jumps by almost half a billion people, the headcount ratio for East Asia doubles, there are substantial increases in Africa and South Asia, and a large reduction in Latin America. The Table shows these numbers for 1993, for which there are estimates using three sets of PPPs, but there are similar large upward revisions for more recent years; for 
example, Shaohua Chen and Martin Ravallion (2008, Table 5) show that for 2005, there are 1,377 million poor people using the latest method, compared with 931 million poor people using the methods in use prior to the latest ICP revision. The size of the earthquakes seems to be increasing.

Let me emphasize again that the general trends in the left-hand side of Table 1 reappear whichever PPPs and poverty lines are used. The shifting of the ground refers only to the level of global poverty, and to its regional distribution. Provided one is prepared to ignore the fact that each new set of estimates makes the world look like a very different place, the global trends are relatively secure, although I shall enter some qualifications in Section VII. Given the clear improvement in the successive ICPs, I would certainly not advocate the retention of outdated and flawed data, and indeed the ICP is far from the only source of uncertainty in the world poverty measures, which depend on the timeliness, availability, coverage, design, and quality of national household surveys, national consumer price indexes, and national accounts. Yet the size of each set of revisions, and the reasonable presumption that future rounds of the ICP will change the picture yet again, raises the question of whether the poverty monitoring system is accurate enough and stable enough to be useful in monitoring progress and for identifying countries and regions where deprivation is greatest.

The ICP revision in 2005 was associated with a substantial increase in the World Bank's measure of global poverty; Chen and Ravallion (2008) write "the developing world is poorer than we thought,” while World Bank (2008b, page 1) says “The new poverty line maintains the same standard for extreme poverty - the poverty line typical of the poorest countries of the world-but updates it using the latest information on the cost of living in developing countries. The new data change our view of poverty in the world. There are more poor 
people." The Chief Economist of the World Bank commented "the sobering news—-that poverty is more pervasive than we thought—means that we should redouble our efforts, especially in sub-Saharan Africa."

Global income inequality also changed with the revision to the ICP. Branko Milanovic (2009), using household survey data, has estimated that the Gini coefficient of income inequality over all the citizens of the world rose from 0.65 to 0.70 as a result of the revision. Figure 1 provides another way of looking at the change and shows population weighted inequality across countries using per capita GDP in PPP dollars as the income measure, what Milanovic calls “Concept 2” inequality, see also Sudhir Anand and Paul Segal (2008). The figure shows the Gini coefficient of population weighted per capita national income inequality, and this would be the global Gini if incomes were equally distributed within countries and the national accounts data and PPP indexes were correct. For a complete accounting of international income inequality across households, within country inequality must also be allowed for although, given the conflict between national accounts and survey data, with incomes in the latter often growing more slowly, it is not obvious how to do so. Milanovic uses only survey data, and finds little change in world inequality in recent decades; procedures that use NAS data, coupled with distributional data from household surveys, find that inequality is declining, see for example Maxim Pinkovskiy and Xavier Sala-i-Martin (2009) for a recent example: neither procedure by itself is credible, see again Anand and Segal (2008) for a discussion of how little we know. For my purposes here, I note that inequality between countries has dominated the total in recent history, see Francois Bourguignon and Christian Morrison (1998), and within country inequality is not affected by the choice of PPPs—at least if we ignore regional price differences within countries—and so 
is not my topic here. The graphs in Figure 1 are falling over time in large part because the per capita national incomes of the world's largest countries, India and China, have been growing very rapidly and moving from the bottom of the world income distribution towards its middle.

The top two graphs in the figure show the two time series using World Bank PPP data before and after the 2005 revision of the ICP. The bottom two graphs use data from the Penn World Table (PWT), and compare version 5.6, which used PPPs referenced on 1985, with version 6.2, which uses PPPs referenced on 1993. This second pair of graphs is chosen to illustrate the 1993 revision to the ICP, which is the one immediately prior to the latest 2005 revision. The Penn World Table uses a different type of PPP than does the data from the World Bank, Geary-Khamis rather than EKS—-which tends to understate the level of global inequality because of Gershenkron or substitution bias, see for example Steve Dowrick and Muhammad Akmal (2005). PWT also uses different rules for updating between benchmark years, and exercises more freedom than does the World Bank in editing growth rates from country national data, e.g. from China; there are no published World Bank data on a 1985 basis. In consequence, the 1993 inequality numbers from the PWT are not identical to the World Bank estimates, but for my purposes, they are close enough, and follow a similar trend. The main point to note is that the revision from 1985 to 1993, like the later revision from 1993 to 2005, moved measured inequality upwards. In fact, the revisions are about the same on both occasions, about 5 percentage points to the Gini coefficient; using Anthony Atkinson's (2003) useful metric, a substantive (as opposed to statistical) offsetting decrease in the Gini coefficient could be accomplished by each country contributing 5 percent of its per capita GDP into a common pool which is then equally distributed among all countries, a proposal that dwarfs even the most ambitious programs for international aid 
The World Development Indicators did not provide data on aggregate household consumption in international dollars prior to 2008, so it is not possible to replicate Figure 1 for per capita consumption. However, World Bank (2008b, pp. 23-5) lists old and new PPPs for household final consumption expenditure in 2005 for 118 countries, and I have used these to calculate the concept two measure of the Gini coefficient for consumption. Here too the revision from old to new PPPs led to a substantial increase in measured inequality, with the per capita consumption Gini rising from 0.48 to 0.56 .

For my analysis here, it is the widening of measured inequality that is the key effect of the 2005 revision of the ICP. On average, rich nations and poor nations moved further apart. Judged from the rich world, the poor world is poorer than we thought, but judged from the poor world, the rich world is richer than we thought; the two statements are equivalent, and the difference depends on nothing more than the choice of numeraire currency. As we shall see, the revision to the ICP, in and of itself, had little effect on the world poverty count.

\section{The construction of international purchasing power parity exchange rates}

In order to understand why the ICP has such a profound effect on our perceptions of global poverty and inequality, we need to understand something about how it works. This section provides a brief account of relevant issues based on Deaton and Alan Heston (2010); comprehensive accounts of the 2005 round are contained in World Bank (2008a), and in the handbooks on the ICP website at the World Bank.

The latest round of the ICP constructed purchasing power parity price indexes for 146 participating countries for 2005. I focus for the moment on the indexes for household consumption that enter into the global poverty calculations. Consumption is divided into 110 
"basic headings," such as rice, bread, clothing, furniture and furnishings, and each basic heading is represented by a list of precisely specified items that lie within it. It is these items that are actually priced by the ICP investigators. The basic headings are the same for all countries, but the detailed lists are different for different regions of the world, of which there were six in 2005; this structure means that the same items are not priced in all 146 countries. For example, fresh mud crabs and fresh squid appear in the Asian list in the fish basic heading, while in Africa, we have Nile perch, catfish, kapenta, and bonga, along with many other fishes. At a first stage, the prices for the detailed lists are aggregated up to give regional "parities” (price indexes or PPPs) for each basic heading. These are in the units of a regional numeraire, e.g. Hong Kong for the Asia/Pacific region, and are the price indexes, with Hong Kong as unity, for each basic heading in each country in Asia/Pacific. For example, fish in Bangladesh is 4.90 taka per Hong Kong dollar, and 4.64 Sri Lankan rupees per Hong Kong dollar in Sri Lanka, while the corresponding figures for gasoline are 2.55 and 3.17. These parities are commodity-specific PPP exchange rates, and there is one for each basic heading in consumption. At a second stage, these parities for basic headings are averaged to give an overall PPP for the country. An important distinction between the first and second stage is that at the latter, the averaging can use expenditures from the national accounts statistics (NAS) to weight together the parities from each basic heading in relation to the amount spent on each. At the first stage, within the basic headings, there are no NAS expenditure data, and aggregation up to the parities for the basic headings must be done without weights.

The procedures outlined above yield a system of PPP exchange rates for each region of the world, with a different numeraire country in each, not a single global system with a single numeraire currency such as the US. In the 2005 ICP, the "gluing together” of the regions was 
accomplished using a third stage, the "ring," in which 18 strategically chosen countries, at least two per region, were asked to price a new, common detailed list of more than 1,100 items. Those prices were then used to link the regions.

Beyond this general outline, I now develop some of the details that I shall need to understand the implications for the measurement of poverty and inequality. At the first, detailed, stage, the ICP collects prices in each country $c$ in region $r$ for basic head $i$ so that there might be $j=1, . . N^{r}$ items in the basic heading (varieties of seafood in the fish basic heading). We can then run a set of country-product dummy (CPD) regressions, one for each basic heading separately by region, of the form

$$
\ln p_{i j}^{c r}=\alpha_{i}^{c r}+\beta_{j}^{c r}+\varepsilon_{i j}^{c r}
$$

in which each price is regressed on a set of commodity (basic heading) and country dummies — with country 1 omitted—so that the parity in region $r$ for basic heading $i$ (with country 1 as numeraire) is given by

$$
p_{i}^{c r}=\exp \left(\alpha_{i}^{c r}\right)
$$

where the suffix $1 r$ identifies the numeraire country in region $r$. If every country in the region prices everything in the regional list, (2) would be a geometric mean of prices in the basic heading for country $c$. But not everyone has fresh (or even smoked) bonga in their local market, so that CPD regression works when geometric means would not. Effectively, (1) “fills in” missing values for items whose prices cannot be found, even to the extent of delivering a comparison of two countries neither of which consumed any item purchased in the other, provided that the items appear together in one or more other countries.

Another problematic issue here is that smoked bonga (or indeed Kellogg's cornflakes, a more important example) may be available, but is rarely eaten in country $c$, so that it is only 
stocked in specialty shops at very high prices. On the one hand, the ICP wants to specify goods very precisely (the actual specification in the African list is "smoked bonga, in simple wrapping, open product presentation, a piece of approximately 200 grams”) so that we are sure we are matching like with like (and not matching a bonga with any old smoked fish) while, on the other, it wants to avoid comparing commonly consumed items with nonrepresentative, rarely consumed, and expensive ones. To try to handle this tension, the ICP asked enumerators to grade the local representativity of each good on a three point scale, with the intent of down-weighting unrepresentative items. A similar system was successfully operated in Europe in 2005, but the rankings from the other regions were not useable, so no correction was made for high prices of possibly unrepresentative goods.

When we move from parities for basic headings to PPPs for countries, the prices for each basic head from (3) are combined with expenditures from the national accounts statistics of each country. In the first instance, this is done for each region separately. The theory here is a multilateral extension of standard bilateral price index formulas in which Fisher ideal indexes for each pair of countries are adjusted so as give a transitive set of international prices indexes, or PPPs, see Deaton and Heston (2010) for an account. The Fisher indexes underlying the multilateral PPPs are "superlative” indexes, Erwin Diewert (1976), which means that there exists a suitably general set of preferences for which they are exact cost-ofliving index numbers. Because the index uses weights from both countries, rather than just one or the other, the use of the Fisher index limits the effects that would result from weighting one country’s prices by expenditure patterns that come from a country or countries with very different relative prices and consumption patterns; if countries had identical tastes, these effects would be the familiar substitution or Gershenkron biases. 
The third and final stage of the ICP brings the regions together into a single set of basic heading and country parities for the world as a whole with everything expressed in the currency of a single numeraire country, the US. This is done by pricing a new common "ring" list of more than 1,100 items in each of 18 countries, Brazil, Chile, Cameroon, Egypt, Estonia, UK, Hong Kong, Jordan, Japan, Kenya, Sri Lanka, Malaysia, Oman, Philippines, Senegal, Slovenia, South Africa, and Zambia. As suggested by Diewert (2008), these detailed ring prices were used in a modified version of the CPD regression (1)

$$
\ln \tilde{p}_{i j}^{c r}-\ln p_{i}^{c r}=\tilde{\alpha}_{i}^{r}+\gamma_{i}^{j}+\varepsilon_{i j}^{c r}
$$

where $\tilde{p}_{i j}^{c r}$ is the ring price for item $j$ in basic head $i$ in country $c$ in region $r, p_{i}^{c r}$ is the previously established regional parity for basic head $i$, from (3), and the right hand side variables are regional and item dummies. Intuitively, each item price in the ring, $\tilde{p}_{i j}^{c r}$, the price of shrimp ( $j$ ) in the fish basic heading $(i)$ in ring country $c$ in region $r$, is converted to the region numeraire currency (e.g. Hong Kong dollars for Asia/Pacific) using the previously established within region parity for fish, $p_{c r}^{i}$ from (2). The regression (3) then picks out the regional log price level for fish, $\tilde{\alpha}_{i}^{r}$, e.g. in Hong-Kong dollars per global numeraire, which is the numeraire of the OECD-Eurostat region, the US dollar. We then have a set of all-region parities for each basic heading, $\exp \left(\tilde{\alpha}_{i}^{r}\right)$, which are unity for the numeraire region (OECDEurostat). These "prices," together with the regional aggregates of expenditures on each basic head expressed in regional numeraire currency, are used in a global multilateral aggregation to give regional PPPs, one index for each region, that allow the within-region PPPs to be scaled up to global PPPs. 
Four specific aspects of this ICP construction are of concern here. First, the absence of weights within basic headings, including the lack of representativity weights, may result in basic headings being priced using high-priced unrepresentative goods that are rarely consumed in some countries. This is a particular concern for the ring, where identical goods are being matched across very different countries. Second, when country PPPs are constructed from the prices of basic headings, the ICP uses expenditure weights from the national accounts. These weights are appropriate for national income accounting purposes, but do not reflect the consumption patterns of people who are poor by global standards. Third, the joining of the regions using the ring information is based on region-wide "super" PPPs in which, for example, there is a price level for Africa or Asia/Pacific relative to the OECD. Measurement errors, or conceptual problems here move whole continents-I think of these as "tectonic" price indexes—and play an important role in determining global inequality. Fourth is an issue to which I shall return only briefly, which is an urban bias in price collection in some countries, particularly large countries such as China.

\section{Global poverty and the consumption patterns of the poor}

To turn the standard PPPs into poverty-weighted PPPs, or P4s, it is necessary to weight the multilateral indexes, not with the expenditure patterns from the national accounts, but with the expenditure patterns of people in each country who live around the global poverty line, patterns that can only come from household survey data. It is also desirable to compute the multilateral indexes (5) using data only from the countries that are in the global poverty counts, so as to avoid the possibility that the P4s used to convert the Indian, Chinese, Indonesian, or Kenyan poverty lines into a common currency would be affected by the 
patterns of demand in Japan, Sweden, or the United States. Indeed, there are no households in rich countries who live on anything close to $\$ 1$-a-day, so it would not be possible to include those countries in the calculation of P4s. Note that because the global poverty line is a PPPconverted average of local-currency poverty lines, and the poverty-weighted PPPs use weights from households near the global line, the line and the P4s need to be calculated simultaneously.

Deaton and Dupriez (DD) (2009) assemble household surveys from 62 developing countries, and match their consumption data to the basic headings in the ICP and then recompute poverty weighted indexes. Their main result is that these P4s are very close to the PPPs: the reweighting to the poverty line makes little difference provided that household survey data are used for both calculations. This may seem surprising given that patterns of consumption for the global poor are very different from the plutocratic patterns of consumption in the national accounts. But that by itself is not enough to generate a difference in the price index or the PPP. Between any pair of countries, the substitution of poverty-line for NAS budget shares will only change the price index between them if the change in budget shares induced by movement down the income distribution is systematically correlated across goods with the price relatives in the two countries. This would happen if we were calculating a price index for a pair of countries, one rich, with low food share and low relative prices of food, and a poor country, with high food share and high relative prices for food (much of food is traded), where the move from a plutocratic to poverty weighting will increase the price level in the poor relative to the rich country. Among a group of countries, all of whom are relatively poor, this effect is typically not pronounced. In effect, although their patterns of 
demand are different, international comparisons of poor households give much the same result as international comparisons of middle income households.

A convenient way to present consumption PPPs is as the "price of consumption," the ratio of the consumption PPP to the average exchange rate in 2005. DD use India as base so that, for example, a figure of 1.692 for Nigeria shows that an Indian converting naira prices into rupees at the official exchange rate would find that consumption prices in Nigeria are 1.692 times consumption prices in India. Over the 62 countries used in DD, and using the price of consumption, the inter-country correlation is 0.913 between the ICP indexes and their preferred P4 indexes. This correlation overstates the difference made by the povertyweighting because there are other important differences between the two procedures. Table 2 shows the steps that lead from one to the other. Starting from results published by the ICP, the first modification is to recalculate using only the 62 relatively poor countries for which DD have surveys, and to calculate the consumption PPPs in a single step for all countries, ignoring the regional structure of the ICP but using NAS aggregate weights, as in the ICP. The correlation between these two NAS weighted indexes is 0.934 , which is better expressed as the root mean square difference between the two sets of consumption prices, which is 0.156 in the first entry at the top left of Table 2. This is more than ten percent of the mean (1.4) of these Indian based consumption price indexes. The next step is to replace the aggregate weights from the NAS by aggregate consumption weights estimated from the household surveys. The RMS difference here, from NAS weights to survey weight, shown in the $(2,2)$ position of the matrix, is 0.065 ; we are now 0.150 from the original ICP, element $(1,2)$. Finally if we move from NAS aggregate weights to poverty-weights, the RMS difference associated with that step is the 0.057 , shown in position $(3,3)$ which also takes us 0.157 away 
from the ICP. (DD also find similarly sized or somewhat smaller RMS differences between different formulas for calculating the PPPs.) The main message here is that the way in which the ICP prices and expenditures are aggregated, and the inconsistencies and differences in definition between national accounts and survey estimates of expenditure patterns are as, or more important in affecting the estimates of consumption PPPs than whether or not they are adapted to the expenditure weights of the global poor.

Table 3 lists DDs consumption prices for India and the eight countries—-four in Asia and four in Africa - that contain the largest numbers of poor people in 2005. Between them, these nine countries contain 74 percent of global poor according to the World Bank’s $\$ 1.25$ a day count. The first column shows the prices of consumption from the ICP; these are the prices used in the World Bank's poverty estimates in Table 1. The second, third, and fourth columns, show the prices of consumption defined above. As is more generally true, the differences between the last two columns—-poverty weighting or not—are not as important as differences between the earlier indexes. The Indian-Chinese price level changes by about 6 percent from the first column to the last. Given the general uncertainty about the estimation of PPPs, this is not large. However, in preparation for some of the calculations to come, it should be noted that small changes in PPPs will have large effects on poverty counts in countries where a large fraction of the population is in the vicinity of the poverty line. India is the most dramatic example, and in 2005, the Indian headcount ratio increases by 0.7 of a percentage point for each percentage change in the PPP so that, for example, a 5 percent change in its consumption PPP applied to a fixed global line would add around 35 million people to Indian and to global poverty. Indeed, an important general point is that poverty counts are sensitive to PPP calculations, to the methods used for aggregating basic headings up to the country level, and 
to the sources of data used, as well as to whether we use poverty weights or not. This sensitivity of poverty counts helps understand why poverty counts can change so much with ICP revisions, but it is not a major factor in answering the question with which I ended Section 2, which is why the 2005 revision of the ICP increased the world poverty count by more than a third. That is the topic of the next section.

\section{Poverty lines and poverty counts}

Most of the increase in the world poverty count with the revision in the ICP can be attributed to two main factors only one of which, the treatment of housing rental, is directly attributable to the ICP itself. Much more important was an increase in the global poverty line. Although the procedure that the Bank used to calculate the global line is the same as previously, the line itself has been increased. Both of the factors are of general interest. The treatment of housing is a major concern for virtually all price index work and will be so for future rounds of the ICP. The procedure for calculating the global poverty line will also determine the future path of the global count, and in particular how the global line changes as countries get richer. I deal with each issue in turn, starting with the least important.

\section{A. Actual and imputed rent for housing}

Housing rental, including imputed rental for owner occupiers, is a difficult (“comparison resistant”) area for the ICP, see Deaton and Heston (2010). For the African and Asian regions, the 2005 ICP had to fall back on an imputation. Because the ICP is primarily focused on obtaining "volume” measures of GDP in international currency, it was decided to impute rental by assuming that, for countries in Asia and Africa, the volume of rental was a fixed proportion of GDP. This is a neutral imputation because, unlike other possibilities, it does not 
disturb the ratios of GDP across countries. However, what is neutral for quantities is not neutral for prices. The parity for the rental basic heading is derived as the ratio of expenditures on rental (which comes from each country's national accounts) divided by the assumed quantity, which is taken by the imputation to be proportional to GDP. For countries that make little or no allowance for owner-occupier rentals in their national accounts, this "imputed" parity will be very low. Table 4 shows the parity for housing rentals relative to the overall parity for consumption for the 15 poor countries whose national poverty lines in international currency are averaged to give the $\$ 1.25$ global poverty line. I also show India and China for comparison; we do not know that these are correct, but it is reasonable for a non-tradable stock like housing to be cheaper than the average consumption item in those countries.

Several of the rental parities in the 15 countries in Table 4 are too low to be credible. For Ghana, the rental parity is less than five percent of the overall parity, it is 11 percent in Gambia, and 12 percent in Tajikistan. In nine of the fifteen countries, the rental parity is less than a half of the overall parity. If we are concerned with the parities and the overall PPP for consumption, rather than with volumes, a neutral assumption would have been one in which the parity for rental was taken to be the same as an average over all consumption, and this can be accomplished by dropping the category and recalculating the PPPs. This raises the PPPs (local currency to US dollars) in Africa and Asia, and more precisely raises the PPPs relative to India of countries in Table 4 whose rental parities are less than 0.602, and relative to China of those whose rental parities are less than 0.832 . The Indian or Chinese equivalent of the local poverty lines of those countries are reduced by an increase in their PPPs, which reduces the headcount rates in India and China, and because they are so large, reduces the global 
poverty count. This (alternative) neutral treatment of housing rental reduces the 2005 poverty count by more than 100 million people.

It should be noted that the treatment of housing is not an error in the ICP, which is focused on producing reasonable estimates of GDP rather than prices or poverty, but it turns into a problem when we move to poverty measurement without making a correction.

\section{B. Setting the global poverty line}

Since the first dollar-a-day poverty counts in 1990, the line has been set by taking the national poverty lines of a group of the poorest countries in the world, converting them to international dollars using PPPs from the ICP, and taking a simple average. Bringing in more countries is arguably an improvement over using India alone, as in Ahluwalia, Carter, and Chenery (1979), though as they argue, the Indian line has been seriously and continuously debated in a way that is not the case for many other countries in the average. Either way, the aim is to find a line that represents absolute poverty, and the idea is that poverty lines in the poorest countries are a reasonable estimate of what that might be. This idea is further supported by the relationship between the PPP value of national poverty lines and the PPP value of per capita GDP or consumption; national poverty lines do not vary much with levels of living in the poorest countries, but beyond some cutoff—-where relative poverty begins to matter as well as absolute poverty—national poverty lines rise with the average level of living, see Ravallion, Gaurav Datt, and Dominique van de Walle (1991), Ravallion (1992) and Atkinson and Bourguignon (2000). This relationship is shown in Figure 2, using data on poverty lines and per capita expenditure levels (from household surveys), assembled by Ravallion, Chen, and Prem Sangraula (2009), who use them to define the current $\$ 1.25$ a day poverty line. Their procedure is to define a cutoff, shown as the line AA in Figure 2, below which poverty lines 
do not decline further, and to compute the global line as the simple average of the poverty lines to the left of AA—which are the poverty lines for the first 15 countries listed in Table 4. This leads to \$1.25 per person per day in 2005 international dollars.

This procedure is unobjectionable for a one-time setting of the global line. Until the most recent revision, the 1990 line was updated using the same group of reference countries, so that revisions to the global line, for example from $\$ 1.01$ to $\$ 1.08$ in Table 1, came entirely from revisions in the ICP, from the 1985 benchmark to the 1993 benchmark. In the latest revision however, Ravallion, Chen, and Sangraula took the opportunity to collect an important new data set of national poverty lines, and to update not only the conversion factors from the 2005 revision of the ICP, but also the group of reference countries whose poverty lines go into the global line. One consequence of the change was that India's recent economic growth allowed it to graduate from the poverty-line reference group, so that India's poverty line no longer contributes to the global line. This updating has unfortunate and unintended consequences.

I illustrate the argument using Figure 2 and by focusing on two of the marked countries, India (population in 20051.1 billion) and tiny Guinea-Bissau (population in 20051.6 million). The line PP shows the $\$ 38$ a month global line ( $\$ 1.25$ a day.) India’s poverty line is a good deal lower than the global line and Guinea-Bissau's a good deal higher. Note that, although there are round to round revisions in the PPPs used to establish the international value of these local lines, the relative position of the lines depends on the domestic procedure that is used to set the national lines in local currency. Over time, as country incomes change, either in reality, or through measurement error, some countries will move across the cutoff line AA. Consider first India, which has a low poverty line relative to its living standards, and suppose that India has recently moved across the line from left to right. At the point where it 
is just on the line, there will be an upward discontinuity in the global poverty line as India drops out of the average, and a corresponding upward discontinuity in the global poverty count, much—but not all—of it from India. Not only is there a discontinuity, but in this particular example, the change is of the wrong sign, with a small increase in Indian incomes causing a large increase in Indian and other countries’ poverty counts. In effect, India and the world have become poorer because India has become richer! Turn now to Guinea-Bissau, and suppose that it becomes richer-through an increase in the world price of cashews, or only apparently so through measurement error — so that it moves across the line AA from left to right. Because Guinea-Bissau has a high poverty line, the global poverty line will decrease, as will global poverty, and this effect turns out to be rather more than 20 times the population of Guinea-Bissau. These problems would not occur if the relationship in Figure 1 were exact, rather than a scatter. With a scatter, the updating procedure violates monotonicity, that if poverty falls in any country included in the counts, and increases nowhere else, global poverty should fall. The current procedure does not satisfy that basic requirement. Nor does it satisfy the property that global poverty should fall by no more than the fall in poverty in individual countries.

An alternative procedure for deriving the global line is to average the available national lines for all of the countries in the counts. This runs the risk of including poverty lines that are too high to be plausible as minimum subsistence requirements, but this can be dealt with by weighting each line by the number of poor people in the country so that, for example, the poverty lines of the countries listed in Table 3 will receive the most weight, with the Indian line — currently excluded from the computation of the $\$ 1.25$ line —-receiving around a third of the total weight. At the same time, very little weight is assigned to tiny countries like Guinea- 
Bissau, whose national poverty lines or estimated PPPs are thereby prevented from having large effects on the global poverty count by bringing millions of Indians and Chinese in and out of the counts. Without endorsing the quality of the national accounts of large poor countries such as India and China — around which there has been much debate-it is surely unwise to place great weight on the quality of the data from at least some of the countries in Table 4.

Tables 5 and 6 show a range of calculations for the global poverty lines and the associated counts. The first figure in Table 5, 19.49 rupees per person per day, is the $\$ 1.25$ poverty line converted to Indian rupees at the Indian rupee to \$ consumption PPP of 15.60. (It should be noted that this is considerably higher than the government of India's own lines for 2004-5, which are 11.77 rupees per day for rural and 17.77 rupees per day for urban.) If we exclude Guinea-Bissau, which in the absence of household survey data cannot be included in the P4 calculations, but use otherwise identical procedures, the line falls only slightly to R19.06 or $\$ 1.22$. If the ICP numbers are replaced by PPPs calculated in a one-step multilateral calculation but using the ICP raw data, but not their regional aggregation procedure, the line falls to R18.98. There is a further drop to R18.05 once we exclude three basic headings that are not covered by household surveys, FISIM (financial intermediation services indirectly measured, the profits of banks and insurance companies), prostitution, and actual and implicit rental for housing. This drop is largely driven by housing rental, and by replacing the neutral volume assumption by the neutral price assumption, as discussed above. Once we switch to surveys as the source for the aggregate weights, but still hold with P3s, and with the unweighted average of 14 poverty lines, the line falls to R17.81. The second row shows the effects of moving to poverty-weighted PPPs, first retaining the unweighted 14 
country averaging, and second with 50 country poverty-weighted averaging. The first step, replacing the $\mathrm{P} 3 s$ with $\mathrm{P} 4 \mathrm{~s}$, leaves the line within the range established in the first row, but the second step, which brings in the Indian and Chinese poverty lines, shows a marked reduction in the global line, to R16.04 which, not surprisingly, lies within the range of the Indian official rural and urban lines.

Table 6 shows the implications of the different lines for the global poverty counts. Given that the US is not, and cannot be, included in the P4 indexes, there is no US to rupee internal P4 to convert international rupees to international dollars. Instead, Deaton and Dupriez (2009, Table 13) calculate "star" PPPs comparing the US with each of the 62 countries they use, with each country's currency first converted into international rupees using the P4s. Star PPPs are computed one country at a time, and are Fisher price indexes between each country and the US, with poverty line weights for the 62 countries, and the national accounts weights for the US, the idea being to compare market consumption in the US - the consumption of the richworld audience to whom the global counts are directed — with the consumption of those near the global line in each country. It turns out that these star rates do not vary much from country to country, so DD use an average to convert the rupee lines back to dollars. Table 6 again starts with the official calculation, somewhat updated from World Bank (2008b), and Table 1, with a global poverty line of \$1.25 in 2005 international \$ and a global count of 1,319 million. The next row shows the global line and counts using P4s and averaging lines over 14 countries; the global line is R18.97 or $\$ 1.064$ and the global count falls to 1,164 million. As we have seen in the step by step calculations in Table 5, the main reason for the drop of 155 million in the poverty count is the change in the treatment of housing. The final row again uses P4s, but now with poverty-count weighted averages of 50 national lines. In this final 
calculation, the global line falls to R16.04 or \$0.922, and the global count to 874 million, twothirds of the number with which we started. Chen and Ravallion (2008, Table 5) report that the World Bank's previous methods—-before the new ICP, and before the change in the poverty line—give a total of 931 million for 2005.

These calculations show that, provided we use a sensible method for setting the global line, neither the wider collection of poverty lines nor the ICP revision has generated any great need to revise our estimates of the prevalence of global poverty. The belief that the new ICP makes the world poorer comes from missing the fact that the updating procedure had increased the global line, and then attributing the increase in poverty to the ICP revision on the mistaken belief that the dollar-a-day line is actually denominated in dollars.

As we saw in Section 2, the ICP revision did indeed make the world look more unequal, and it reduced the size of poorer economies relative to richer economies. In that sense, judged from a rich country standpoint, the "developing world" does indeed appear to be poorer. However, global poverty is measured relative to standards set in the poor countries themselves, so that the apparent expansion of inequality cannot, and does not increase the global poverty count. The count is invariant to any inequality expanding uniform downward rescaling of the international dollar value of consumption in countries in the count relative to the excluded rich countries. Because the expansion in inequality comes about through increases in the measured price levels in poor countries relative to rich countries, this shows up in the poverty calculations through a real decrease in the global poverty line. The $\$ 1.08$ in 1993 prices, which would have been $\$ 1.46$ in 2005 prices if it had been indexed for the US CPI, is in fact only 92 cents in Table 6. This is a measure of the extent to which the ICP has 
revised upwards the price levels in poor relative to rich countries, which is the issue to which I turn in the next section.

\section{Quality and inequality around the world}

Understanding why the ICP has increased measured global inequality is more difficult than understanding why measured poverty has changed. Several different factors are at work, and it is not always clear how to assess the contribution of each. Any change from the 1993 ICP involves not only the new procedures, but also the old ones, many of which-especially the linking of the regions — are known to have been ad hoc and unsatisfactory. I shall focus on the 2005 round, and discuss and quantify the effects of several aspects of the way the indexes were constructed.

Figure 3 shows the revisions to the PPPs in relation to country living standards; it shows the ratio of new to old GDP PPPs for 2005 taken from the 2008 and 2007 World Development Indicators, respectively. A similar graph for the consumption PPPs is given in Chen, Ravallion, and Sangraula (2009, Figure 4.) Figure 3 shows a strong negative relationship between the upward revision in the PPP for GDP, on the vertical axis, and log GDP per capita on the horizontal axis, which implies that the GDP per capita in international dollars tended to be revised downward in poor countries relative to rich countries, which is why inequality increased. (The negative relationship would be even steeper using the old estimates of per capita GDP, according to which the poorest countries were richer than shown.) Relative to the rich countries, poor countries became poorer; this does not increase the measure of global poverty given that global poverty is assessed by poor world standards-but it does increase the estimate of global inequality (and reduce the value of the global poverty line below its value if updated by the US CPI.) The figure also shows that the largest revisions are in Africa 
and Asia; the average ratios of new to old are 1.42 for Africa and 1.33 for Asia-Pacific. The largest seven revisions are in Africa, and there are 18 African countries in the top 25, the others being Cambodia, Nepal, Bangladesh, Philippines, China, Tonga, and Fiji, all except Tonga (which was not benchmarked in the 2005 ICP, but was imputed) are in the Asia-Pacific region. Since Africa and Asia were linked to the other regions using regional PPPs—one for each region—calculated from the ring using Diewert's method—-these regional PPPs are a natural point of investigation for investigating the increase in inequality. By the same token, measures of world inequality are sensitive to these regional PPPs; for example, if the revision to the regional PPPs for Africa and Asia-Pacific had been half their actual size, so that the ratios were 1.21 and 1.165 rather than 1.42 and 1.33 , half the difference in the standard deviation of logs in per capita GDP would disappear. Without the upward revisions to the African and Asia-Pacific PPPs, there would have been no increase in measured inequality.

\section{A. Country coverage, imputations, and inequality}

The 2005 ICP has price data for 146 countries, many of which were imputed in earlier rounds, either by comparison with countries at similar level of development, or by updating old data, or some combination of the two. For countries without benchmarks, the PPP correction factor, the ratio of PPP to exchange rates, is imputed from a regression of the logarithm of the correction factor on the logarithm of per capita GDP at market prices. (Other variables are also included, see Changqing Sun and Eric Swanson (2009) and Deaton and Heston (2010) for more details.) These imputations target the logarithm of PPP, or equivalently the logarithm of per capita GDP in international dollars, and deliver unbiased estimates in ideal conditions. However, the imputed values will have less cross-country variations than the unobserved true 
values. If $\ln p_{y}$ is the logarithm of the price of GDP—the ratio of the PPP to the average exchange rate-the regression for imputation in its simplest form is

$$
\ln p_{y}=\beta_{0}+\beta_{1} \ln y_{A}+\varepsilon
$$

where $y_{A}$ is per capita GDP in US \$ converted at market exchange rates; using the World Development Indicators, $\beta_{1}$ is typically estimated to be around 0.25 . Imputed per capita GDP in international prices is

$$
\ln \hat{y}_{I}=-\hat{\beta}_{0}+\left(1-\hat{\beta}_{1}\right) \ln y_{A}
$$

Compared with the actual $\ln y_{I}$, (5) introduces variance through the estimation of the parameters, an effect that is likely to be small, but removes variance because the variance of $\varepsilon$ is not included in the imputation. Over successive rounds of the ICP, as fewer PPPs are imputed, and more actually measured, measured inequality will rise. The variance of $\varepsilon$ estimated from (5) using the pre-revision 2005 data (and including the imputations) is 0.084 , which needs to be multiplied by the change in the fraction of covered countries (about 0.25 ) before it is compared with the increase in the actual variance of log GDP in 2005 of 0.370 . So the reduction in the share of countries imputed cannot explain more than a small part of the increase in measured inequality.

\section{B. Comparisons between rich and poor countries in the ring}

The most important question for international comparisons of prices is how to make useful comparisons across widely different countries, countries in different regions of the world, at different levels of per capita GDP, and with different patterns of consumption and of relative prices. The regional structure of successive ICPs means that this issue is most serious when the regions are linked because, in spite of there being a good deal of heterogeneity within 
some regions, e.g. Hong Kong and Nepal are both in Asia-Pacific in 2005, the widest disparities are across regions. To investigate this further, we need to look in some detail at the operation of the "ring" in the 2005 ICP, the collection of a more than a 1,000 precisely specified identical items in eighteen countries distributed over the regions.

Past rounds of the ICP have been criticized for not comparing like with like; a cotton shirt, a pair of sandals, or brain surgery in Cameroon or Senegal are plausibly of lower quality than the same items in Japan or Hong Kong, and comparing the prices of such loosely defined items arguably overstates living standards in the poorer countries relative to the rich. In the 2005 round, the ring list, like the regional lists, used precisely specified definitions of goods and services in order to avoid quality mismatching, and this is cited as an important reason for the differentially large increase in the PPPs of poor countries, World Bank (2008b, p. 1), Ravallion, Chen, and Sangraula (2009, p. 178). We can see how this works by looking at the 18 ring countries as a group, and calculating a set of PPPs for them using the standard methodology, the CPD regressions (1) and (2) to get parities for each basic heading, followed by aggregation to multilateral PPPs for those 18 countries alone. Because the US is not a ring country, I select the UK as base, and calculate the "price level” of consumption goods and services included in the ring list for each of the ring countries relative to the UK; this is defined as the ratio of the PPP in local currency per pound sterling divided by the market exchange rate of local currency per pound sterling. Numbers less than one indicate that a British tourist would find the value of converted pounds worth more than in Britain.

The log price levels are plotted against the logarithm of per capita GDP in Figure 4 which shows that Cameroon, Kenya, Senegal and Zambia are outliers in having high price levels relative to their levels of per capita GDP; the regression line is fitted to the other 14 ring 
countries, and is close to the comparable regression (4) estimated for all countries in the 2005 ICP. More generally, the PPPs and price levels for the poorest countries are higher when calculated from the ring alone than they are in the ICP itself, where the ring prices work only through the overall regional PPPs. Particularly notable is Cameroon, where the price level from the ring alone, 0.673, is higher than Estonia and almost as high as Hong Kong; indeed, if the ring calculations are done using geometric mean price indexes instead of the CPD in (1), the price level in Cameroon is higher than the price level in Hong Kong, an implausible result given the relative levels of GDP in the two countries.

The immediate concern with these high price levels is that, in the attempt to match goods precisely across such diverse countries, the ICP may be pricing high-end "western” goods in poor African countries where, if they can be found at all, are only available in a few specialty stores in the main city. The specifications in the list make this seem plausible. For example, among the items successfully priced in Cameroon were ( $a$ ) frozen shrimp (Fish basic heading: 90-120 shrimp per kilo, pre-packed, peeled), (b) Bordeaux red wine (Wine basic heading: Bordeaux supérieur, with state certification of origin and quality, alcohol content 11-13\%, vintage 2003 or 2004, with region and wine farmer listed), (c) a frontloading washing machine (Major household appliances whether electric or not basic heading: capacity 6 kg, energy efficiency class A, Electronic program selection, free selectable temperature, spin speed up to 1200 rpm, medium cluster well-known brand such as Whirlpool,) and (d) Brand: Peugeot/ Model: 407 Berline/ Edition: Petrol 2.0 liter 16v 140 CV/ Type: Saloon/ sedan/ Engine: 1997 cc; kW/ bhp: 103/ 138/ Doors: 4/ Gears: Manual/ 5/ Standard equipment of basic edition:/ ABS: Yes/ Air condition: Yes/ Automatic climate control: Y. 
Listing such specifications is not the same thing as establishing that they are responsible for overstating prices or price levels in some poor countries, let alone that they are responsible for overstating measured income inequality in the world. One way to look more deeply is to examine the bilateral price indexes that go into the multilateral indexes. In this context, the Törnqvist index, which can be decomposed into the contributions from each good, is more useful than the Fisher index, which it closely approximates. The log of the bilateral Törnqvist index for country $c$ with country 1 as base is

$$
\ln P_{T}^{c}=0.5 \sum_{n=1}^{N}\left(s_{n}^{1}+s_{n}^{c}\right) \ln \frac{p_{n}^{c}}{p_{n}^{1}}
$$

so that we have

$$
0=0.5 \sum_{n=1}^{N}\left(s_{n}^{1}+s_{n}^{c}\right)\left(\ln \frac{p_{n}^{c}}{p_{n}^{1}}-\ln P_{T}^{c}\right)=\sum_{n=1}^{N} \gamma_{n}^{c}
$$

$\gamma_{n}^{c}$ is a measure of how much good $n$ moves the overall index above or below the mean. Table 7 shows the largest positive and negative values for the four outlying African countries in Figure 4.

The most influential basic headings are mostly those that would be expected. Passenger air travel and automobiles are traded goods and, like telephone services, are heavily taxed in much of Africa. Conversely, services—restaurant meals, hairdressing, and domestic serviceare relatively cheap, as are locally grown foods like fresh vegetables. Precise quality matching may contribute to the high prices - for example in the specification of automobiles, and it probably does so in the "other cereals” basic heading (in Table 7 in Kenya, but also important in other countries), which contains a number of items (Frosted flakes, Kellogg's cornflakes, self-rising flour) that may not be representative of African consumption. But Table 7 identifies a different issue that is probably more important, which is that the PPP of a country 
can be strongly affected by the prices of an item that has very little consumption in that country. Air travel accounts for between 0.28 (Kenya) and 0.89 (Cameroon) percent of total consumption in these four countries, and somewhat more in the part of consumption covered by the ring prices, but superlative indexes use weights from both base and comparison countries so that, when these countries are compared with Britain, the high relative price of air travel-in Cameroon more than 11 times higher than the average Cameroon to British price ratio-is weighted by the average of the Cameroon and British share. In consequence, air travel raises the overall (pairwise Törnqvist) price level by 4.2 percent. With Törnqvist indexes, this can happen even when the NAS report no consumption on the item-see catering services in Zambia in Table 7. The Fisher index is not well-defined in this case, but the same general phenomenon occurs, with the budget share from the comparison rich country powering up the price level of a rarely consumed commodity in the poor country.

At this point, it is necessary to ask what these indexes are trying to do, why it is a good idea to match goods so precisely, and why these sharply different budget shares are such a problem. On the latter, the theorems underlying superlative indexes, that they provide good approximations to general cost-of-living indexes, require identical homothetic tastes. In that case, the budget shares would be the same in all countries up to price effects, and the second problem would not occur. When tastes are identical but not homothetic, the superlative index approximates the cost of living for a level of living intermediate between the base and the comparison which, when we are comparing Cameroon or Zambia, with Britain or Japan, is not obviously helpful in the sense that it over-weights the cost of living in Cameroon and Zambia. 
The precise matching of quality is also without clear theoretical foundation, though it certainly provides an answer to the question that it asks, which is what is the average price difference for identical items in the two countries. From a welfare perspective, this may not be the answer that we want. Consider, for example, an imaginary broad basic heading called "cereals," among which there is a staple food in all countries, with some countries choosing wheat, some rice, some maize, and so on. Suppose too, as is broadly true in fact, that the calorie and nutritive content of a kilo is the same, no matter which cereal we choose. In "wheat" countries, rice is rare and expensive, and vice versa. To fix ideas, suppose that a kilo of rice is four times the price of a kilo of wheat in a wheat country. Without weights within the basic heading, the price of cereals from a geometric mean index will be twice the price of wheat, even though almost all consumption is of wheat. For welfare purposes, the price of cereals is better represented by the minimum price in the basic heading, not its geometric mean. Such a procedure might be feasible for foods, where we could plausibly summarize the function of the good by its calorie content, but for other goods is infeasible for the same reason that quality adjustment is so hard in general, that without a "simple repackaging" interpretation of quality differences, Franklin Fisher and Karl Shell (1971)—which is what we can do for the wheat and rice example - there is no non-controversial way of qualitycorrecting price differences. Matching identical goods does not do the job if those goods are used in different ways in different countries, and the problem is intractable without some way of mapping (widely different) goods into common functionings. 


\section{Tectonic regional PPPs}

In practice, Table 7 overstates the influence of individual basic headings on the actual PPPs; pairwise price indexes are not multilateral price indexes and, more importantly, the ICP uses the ring prices, not country by country, but through equation (3), which averages by region the ratios of the ring basic heading prices to the within-region basic heading prices, so that high prices in one country can be offset by low prices elsewhere. Nor does the ring include items that cannot be priced directly, including rental prices of housing. The ICP supplies the regional prices for each basic heading, calculated from (3) for ring items, and by various imputations and use of "reference" prices for the other items, so that I can repeat Table 7 for the bilateral price indexes for consumption between Africa and the OECD, and Asia and the OECD. In their adjusted multilateral form, these regional PPPs are the numbers that are used to scale up the within-region PPPs, and are obviously important for measuring inequality, because they move whole areas of the world up or down in concert. Table 8, which is in the same format as Table 7, shows the influential basic heads for Africa and for Asia-Pacific relative to the OECD, again using the Törnqvist to illustrate.

Not surprisingly, some of the same goods in Table 7 reappear in Table 8, because their prices are high throughout Africa, but several of the basic headings not included in the ring play a large part in shaping the regional PPPs. Perhaps most worrying is the role of actual and imputed rentals of housing, which is bottom of the African list, reducing the African to OECD price level by 4.2 percent, but top of the Asia-Pacific list, raising the Asia-Pacific to OECD price level by 5.9 percent. As we have already seen, these housing parities are imputations, and the low figure for Africa comes from the fact that several African countries do not impute rents in their national accounts. The various medical services that also appear at the bottom of 
the list are almost certainly genuinely cheap, but the quality question again arises because these services are not precisely matched as in the ring list. While precise matching is not the answer, neither is the assumption that the same medical procedure is of the same quality in Zambia and Britain. Pharmaceuticals, which are priced in the ring using precise specifications (Acetaminophen, Acetylsaicylic acid, Aciclovir, Amitriptyline, Amoxicillin, Artesunate, Atenolol, and so on through the alphabet, with international, national, and generic brands for each), would have shown up in Table 7 given a few more rows, and like passenger travel by air, have a tiny budget share in Africa—although not in Asia—so that their contribution to the regional PPP is being driven by the share in the OECD, not the share in Africa. That pharmaceuticals and motor cars are more or less offset by housing in Africa hardly builds confidence in the numbers, though it is hard to see any evidence in Table 8 that would support the idea that prices in Africa are systematically overstated. The large influence of housing in Asia seems much harder to justify.

Table 8 does not deliver any obvious culprit whose adjustment would have a large effect on global consumption inequality, though it does demonstrate the fragility of the estimates. For example, if we were to scale up all countries in Asia-Pacific by 5.9 percentcorresponding to the assumption that the rental parity is the same as in the OECD—-the population weighted international (Concept 2) Gini coefficient falls from 0.543 to 0.537 , a substantial shift, but small relative to the change between the two rounds of the ICP. A 5.9 percent boost to all countries in the African region delivers even less, reducing the Gini from 0.543 to 0.542 . However, when we assess the overall uncertainty about inequality, there are a number of other factors that need to be taken into account, particularly concerning China and India. China collected only urban or peri-urban prices, and Deaton and Heston (2010) argue 
that it would be reasonable to increase Chinese GDP by 10 percent on these grounds alone; indeed, both the World Bank’s most recent poverty calculations, and those by Deaton and Dupriez make a similar correction. There is a conceptually similar, although smaller, urban bias in the prices collected in India. It also turns out that if we replace the ICP calculations by a single global multilateral calculation using the basic heading prices from the ICP, both Indian and Chinese GDP are increased by six percent. If we make a rough correction for all of these issues, raising Asia/Pacific and Africa by 5.9 percent, then China by 20 percent (urban bias plus single bias from regional calculation), and India by 15 percent (same reasons as China), the Gini coefficient falls from 0.543 to 0.524 . These calculations are for GDP; some of the corrections would have smaller effects for consumption, and some larger.

The calculation in which all the corrections are done independently probably overstates the uncertainty about the Gini coefficient, although I find it hard to feel confident about even that. Yet earlier work by Albert Berry, Bourguignon, and Morrison (1983) also showed that Gini coefficients were quite insensitive to choice of international prices, so it is possible that the large change in measured inequality in the 2005 round does not come from any deficiency in the latest ICP. Yet the uncertainties in Table 8 are disconcerting, particularly because they move whole continents, as are the theoretical and empirical uncertainties about quality correction and weighting that emerge from both Tables 7 and 8 . What is disconcerting is not the inability to find a cause or group of causes for the increase in measured inequality, but rather the sense that all of the intercontinental comparisons are fragile, and can easily be disturbed by factors that we do not know how to handle. 


\section{Why don't we just ask people?}

I now return to the main theme, the question of poverty measurement. My investigation of the ICP has shown that there are a number of ICP related questions about the poverty counts. But uncertainty about PPPs is not the only source of sensitivity in poverty measures. The national poverty lines are treated as precise cut-offs, but the discussions that lead to them could sometimes be better characterized as specifying only a range of answers. At least some of the poverty lines from the poorest countries owe little to well-informed local democratic discussions, but are set using standard technical rules based on the expenditure levels at which households typically meet expert-specified nutritional norms. Such lines have many conceptual problems, for example if people do less heavy labor as they become better off, they may need fewer calories, which would lead to an increase in a poverty line defined as the level of expenditure at which fixed "calorie needs" are met, and thus to an apparent increase in poverty, exactly contrary to the true state of affairs, see Deaton and Jean Drèze (2009) for a discussion of the Indian case. At the same time, small changes in lines can have large effects on the counts; more generally, it is hard to justify treating people so differently whether or not they happen to fall on one or the other side of a largely arbitrary line.

Poverty counts can also be very sensitive to survey design. Given a global line, the contribution of a country to the world count is the number of people whose household per capita expenditure lies below the local value of the line, a number that is estimated from household surveys. Yet some surveys collect data on income, not on consumption, most countries do not have regular annual surveys, and in many cases, surveys change over time in ways that make the counts non-comparable, for example by being collected in different parts of the year, collecting different lists of goods, or covering different selections of the 
population. There are long-standing questions about the ability of household surveys to capture consumption or income, even to the extent of showing an increase in poverty when the opposite is true, N. S. Jodha (1988). Survey means are often inconsistent with comparable means from the national accounts, and although there are certainly errors in both, there is often widespread skepticism about the accuracy of the survey distributions with growing concerns in some countries about item and respondent non-response. Another example comes from the Indian National Sample Survey which, in the late 1990s, experimented with a 7-day recall period for food and some other items in place of the 30-day period that had long been their standard. This change resulted in sharp increase in the reported monthly flow of expenditure, enough to remove more than 175 million Indians from the national poverty count; the effect would have been larger still if the poverty line had been mechanically reset using the standard nutritional approach, Deaton (2001, pp 139-41). Yet recall periods are far from standard across countries, so that we should regard global poverty estimates as very rough, and not be surprised by classification errors involving hundreds of millions of people.

The survey based counts cannot satisfy another demand, which is for annual monitoring of world poverty. The World Bank updates its global poverty counts by scaling up the latest survey distributions by growth factors taken from the NAS, but the inconsistencies between survey and NAS growth rates in many countries means that such estimates are potentially subject to substantial revisions when the new survey data are collected, and it is unclear whether such estimates provide any new information beyond the consumption and income data in the NAS which are themselves of uneven quality and timeliness. Yet international organizations and NGOs regularly make claims about the effects on world poverty and on world hunger of current events-most recently the rise in food prices and the financial crisis; 
these claims are essentially extrapolations using evidence whose pertinence can reasonably be questioned.

Given all of the problems, it is worth reconsidering the idea that people themselves seem to have a very good idea of whether or not they are poor. Indeed, the poverty lines set by politicians and bureaucrats are often informed by community ideas of what is needed to get by, even if they are often subsequently justified by more "scientific" supports. There is also a long and distinguished tradition, based on the work of Bernard van Praag (1968), of turning self-reports about income adequacy into poverty lines, see Theo Goedhart, Victor Halberstadt, Arie Kapteyn, and van Praag (1997) who developed the procedure, which has been used among others by Klaas de Vos and Thesia Garner (1991) to compare the US and Holland, and extended by Menno Pradhan and Ravallion (2000) to compare Jamaica and Nepal. So there is something to be said for directly asking people around the world how their lives are going, whether they have enough, or whether they are in financial difficulty, and in cases where there are reliable income data, turning those reports into poverty lines. There are two immediate concerns with such measures in the current context. One is adaptation or the use of relative standards, so that people in rich countries might report outcomes that are much the same as people who are objectively much worse off. This is a serious concern, but it is subject to empirical enquiry, at least in part. The second concern is practical, how and by whom such data might be collected. There currently exist a number of potentially usable international data sets that collect data on various aspects of wellbeing, such as the Eurobarometer, or the World Values Survey. But neither of these has global coverage, and the global data in the World Values Survey is not available every year nor does it always use nationally representative 
samples. These deficiencies have been recently addressed by the Gallup organization, which has been running the Gallup World Poll annually since 2006.

The World Poll (WP) aims to collect uniform data every year from a random sample of all of the people of the world. To this end, the WP has posed the same set of questions to randomly selected national samples of adults from 154 countries; in most cases, the sample sizes are around 1,000 individuals, with a few countries larger and a few countries smaller. Not all countries are surveyed in every year; there were 130 in 2006, 101 in 2007, 125 in 2008, and 72 (with data processed at the time of writing) in 2009. There are 87 countries that were present in all of the first three years and 50 (so far) in all four. Several of the questions address individual wellbeing, and those that I examine here are as follows: (a) the "ladder" question, which asks people to imagine a ladder whose bottom rung, 0 , represents the worst possible life for you, and whose top rung, 10, represents the best possible life for you, and to report on which rung they stand at the present time; $(b)$ Have there been times in the past twelve months when you did not have enough money to buy food that you or your family needed? (yes/no); (c) Which one of these phrases comes closest to your own feelings about your household's income these days? Living comfortably on present income, Getting by on present income, Finding it difficult on present income, or Finding it very different on present income; $(d)$ Are you satisfied or dissatisfied with your standard of living, all of the things that you can buy and do? The WP also has a single income question, but it is frequently missing, and not too much weight should be placed on the non-missing values so, rather than calculate poverty lines, I work with the questions directly. It should be noted that the fact that the questions are identical in all countries does not imply that they are not interpreted differently in different countries. 
In Deaton (2008), I used the 2006 data to show that there was a close, and approximately linear, relationship between the national average value of the ladder and the logarithm of per capita GDP in international dollars, and Betsy Stevenson and Justin Wolfers (2008) subsequently showed that the relationship also holds within countries using the WP income data. These studies show that it is not true that there is (complete) cross-national adaptation of ladder scores; poorer countries, and poorer people, have lower ladder scores so that, for example, the range of national average scores extends from 8.0, 7.8, and 8.0 in Denmark from 2006 to 2008, to 2.8 in Togo, 3.0 in Sierra Leone, and 3.2 in Zimbabwe, all in 2008. The Danish mean is almost three standard deviations above each of these three African means. The relationship between average ladder and the logarithm of per capita GDP in the 2006 data is also present in the 2007 and 2008 rounds. A lack of (at least complete) adaptation also characterizes the other measures. Figure 5 shows a scatter plot of the log of per capita GDP against the fraction of respondents who reported that they were dissatisfied with their standard of living; the lightly-shaded circles are for 2006, the darker circles for 2007, and the very dark circles are for 2008. Table 9 shows the correlations with the log of per capita GDP and the various measures in each year for which they are available and, in the bottom panel, the correlations between growth of per capita GDP and the changes in the measures.

All of the self-reported measures are strongly correlated with log income in levels, which is important because it demonstrates that there is either no adaptation or that adaptation is sufficiently limited so that these measures are usefully correlated with standard objective measures of living standards. Changes in self-reported measures are essentially uncorrelated with changes in the log of per capita GDP, year by year or, for the three measures where we have them, over the two year period from 2006 to 2008. This could be interpreted as evidence 
that the self-reported measures are invalid, and the lack of correlation between changes in the ladder and changes in income is consistent with adaptation in life-evaluation over time (though not apparently over space) as first found by Richard Easterlin (1974). Clearly our three years of data are insufficient to settle the Easterlin hypothesis one way or the other. Both per capita GDP and the Gallup measures are subject to sampling and non-sampling errors, so once again we will need larger and longer-term changes to give a clearer picture. It is also not clear how well-correlated with income we would either expect or want these measures to be. Indeed, if these measures were perfectly correlated with average income, they would not be useful; we are attempting to measure something other than income, something that holds out the hope of measuring the living standards near the bottom of the distribution around the world.

On the supposition that the Gallup measures provide a useful indication of how people see their own lives, I conclude by using them to document changes in perceptions from 2006 to 2009 an exercise that, at the least, illustrates the possibility for real time global monitoring. In order to use the incomplete 2009 data, and to allow for the fact that not all countries are included in every year, I estimate a population-weighted year and country model in which the national average of each indicator is regressed on a set of country dummies and a set of year dummies, with national population as weights. I do this for the whole world, and for each of the standard World Bank regions of the world; the average predictions for each year then serve as the measures of living standards in the aggregate under consideration. The results are shown in Table 10. For the world as a whole, 2007 was a better year than 2006; in 2008, more households reported being in difficulty, and being dissatisfied with their living standards, and these reports were worse still in 2009. The number without enough money for food continued 
to fall into 2008, but like the difficulty and dissatisfaction measures, was worse in 2009 than in 2008. This pattern varies somewhat over the other two regions, with South Asia resembling the world as a whole, and sub-Saharan Africa looking uniformly worse, with 2008 worse than 2007 and 2009 worse still. Without any other measures, I have no way of cross-checking these numbers, but they are certainly not transparently incorrect. They agree with the poverty rankings in placing sub-Saharan Africa in a worse position than South Asia on all measures, and they are consistent with negative effects of increases in world food prices in 2007-08, further exacerbated by the effects of the financial crisis of 2008-09. These effects appear to have been more severe in Africa than in South Asia.

\section{Conclusion}

Particularly in my discussion of international inequality, I emphasized the difficulties of making comparisons of real income between countries, especially countries with very different relative prices and economic structures. The difficulties here may be more than practical ones, and perhaps we are aiming too high when we try to construct a real income scale on which every country in the world can be placed. For example if we look at price indexes for domestic absorption in the US and Tajikistan, the ratio of the Laspeyres to the Paasche index is 9.6, Deaton and Heston (2010, Table 2). This is the same as saying that the ratio of US to Tajik domestic absorption is 9.6 times as large when measured in US prices as it is when measured in Tajik prices. The use of superlative multilateral price index "solves"

this discrepancy, essentially by splitting the (log) difference, but the meaning of such averages is obscure, as we have seen. None of this challenges the usefulness of comparisons between similar countries, such as between the US and Canada, or the members of the OECD. The comparison between the US and Tajikistan is perhaps of limited interest, but that is not true of 
the US and China or the US and India, where the Laspeyres to Paasche ratios are "only" 1.66 and 1.61. In 1949, Richard Stone wrote "Why do we want to compare the United States with, say, India or China? What possible interest is there in it? Everybody knows that one country is, in economic terms, very rich and another country very poor; does it matter whether the factor is thirty or fifty or what?" and goes on to conclude that "I do not expect a very rapid resolution of the intellectual problems of making welfare comparisons between widely different communities." While Stone certainly did not anticipate the major developments in the ICP over the last 60 years, his words may have been prophetic, though he would probably have been well satisfied with the range of 1.66 or 1.61 to 1 that we get for India and China. Yet even these margins of uncertainty ignore the other problems of the ICP, such as the treatment of housing, of the productivity of government services, of urban bias in pricing, and the question of what we are doing when we match specifications so carefully.

More formally than Stone, but along the same lines, Amartya Sen $(1973,1976)$ has suggested that we not try to make complete orderings between countries, let alone compute the ratio scale real income numbers on which poverty and inequality comparisons rest. Instead, he argued for establishing the partial orderings that can be obtained from pairwise comparisons of countries, establishing that one is richer than the other, or cannot be ranked, using the value of each countries commodity vector at the other country’s prices.

At the same time, there is clearly much that is feasible. PPP comparisons between broadly similar countries, for example within regions, are on relatively firm ground, and may be sufficient to support cross-country regressions within subsets of the world, if not for all countries pooled together. PPPs for the poorer countries in Africa or in Asia may be good enough to support global poverty counts, at least provided the uncertainties are recognized. 
Probably the most urgent area for the poverty counts is not the ICP, but the improvement in the consistency and timeliness of household surveys, and the upgrading of national accounts. We have come a long way since Simon Kuznets (1955) apologized in his Presidential Address to the Association for "the meagerness of reliable information presented," but there is still much to be done. It is also clear that more use should be made of monitoring surveys, such as the Gallup World Poll.

What about the poverty counts that have been a running theme of this lecture? I have shown that the recent 50 percent increase in the counts had very little to do with revisions to the ICP, and nothing at all to the fact that the ICP made the developing world as a whole uniformly poorer relative to the rich world. With no change in the global poverty line, or with a more appropriate updating method, there would have been no sharp discontinuity in the counts. It is possible that the upward revision in levels is unimportant, provided that the downward trend in poverty remains the same, but I do not believe that this is the case. Because there are nearly 200 million Indians who live between \$1.00 and \$1.25 a day, the increase in the line adds many more Indians to the counts than it adds Africans. Although the prevalence of poverty remains higher in sub-Saharan Africa, the relative "Indianization" of poverty (or rather "re-Indianization” of poverty, see Table 1) is likely to change the terms of the aid debate. Indeed, the proportional rate of poverty decline in India is lower with the higher baseline, so India is no longer on target to meet the first Millennium Development Goal, Himanshu (2008). More generally, the number of poor people in the world is widely quoted in public debate, so that arbitrary_-and poorly understood_changes undermine any usefulness that these numbers might otherwise have had. 
How should the global poverty line be set in the future? There are two quite different approaches, depending on whether we take our standard from the poor world—as in the current counts—or from the rich world, which is my own preference. In the former, the global line is linked to national lines of poor countries, but given its claims to be an absolute standard, it should not move upwards as countries become richer. One simple possibility would be to use the current Indian line in rupees, or at least a population-weighted average of its rural and urban lines as was done in the first global counts by Ahluwalia, Carter and Chenery (1979). If India revises its poverty line upwards as it gets richer, the world line would continue to be the original Indian line, and the world count would simply be the number of people in the world living below the poverty line set in India when a large fraction of its population was destitute. If the Indo-centric approach is not acceptable, the world poverty line could remain, as now, an average of poverty lines from poor countries although, once again, those poverty lines need not and should not be changed over time; this is what was done until the current revision. There will still be changes in the global line as successive ICP revisions change the relative PPPs of poor countries, something that cannot be avoided.

The alternative procedure would be to make the global poverty line in fact what it is widely perceived to be, one international dollar per person a day. Whatever its origins, it would in future be updated by the US CPI only, so the global line would be a dollar in 2005 prices. If this rule had been in place, the 2005 revision, by making developing countries poorer relative to the US, would indeed have made the "developing world" appear to be poorer, and would have avoided much confusion about what had actually happened, not least the confusion within the World Bank itself. Since the dollar a day counts are used almost 
entirely by rich world NGOs and international organizations, denominating the poverty line in dollars (or perhaps Euros) would better match the measure to its intended audience.

\section{REFERENCES}

Ahluwalia, Montek S., Nicholas G. Carter, and Hollis B. Chenery, 1979, "Growth and poverty in developing countries,” Journal of Development Economics, 6, 299-341.

Anand, Sudhir, and Paul Segal, 2008, "What do we know about global income inequality?" Journal of Economic Literature, 46:1, 57-94.

Atkinson, Anthony B., 2003, "Income inequality in OECD countries: data and explanations," CESIfo Economic Studies, 49:4, 479-513.

Atkinson, Anthony B., and François Bourguignon, 2000, "Poverty and inclusion from a world perspective,” in H. De la Largentaye, P. -A. Muet, J. -F. Richard, and J. E. Stiglitz, eds., Governance, equity, and global markets, Paris. La Documentation Française.

Berry Albert, François Bourguignon, and Christian Morrison, 1983, “The level of world inequality: how much can one say?” Review of Income and Wealth, 29:3, 217-41.

Blank, Rebecca M., and Mark H. Greenburg, 2008, "Improving the measurement of poverty,” Brookings Institution, The Hamilton Project, DP 2008-17.

Bourguignon, François and Christian Morrison, 2002, "Inequality among world citizens, 1820-1992,” American Economic Review, 92, 727-44.

Chen, Shaohua, and Martin Ravallion, 2000, "How did the world's poorest fare in the 1990s?” World Bank Policy Research Working Paper 2409, Washington, DC. (Aug.) http://wwwwds.worldbank.org/external/default/WDSContentServer/IW3P/IB/2000/08/26/000094946 00081406502730/Rendered/PDF/multi_page.pdf

Chen, Shaohua, and Martin Ravallion, 2008, “The developing world is poorer than we thought, but no less successful in the fight against poverty,” World Bank Policy Research Working Paper 4703, Washington, DC. The World Bank (Aug.) http://wwwwds.worldbank.org/servlet/WDSContentServer/WDSP/IB/2009/08/05/000158349_200908 05133945/Rendered/PDF/WPS4703.pdf (Downloaded, January 7th, 2010.)

Citro, Connie F., and Robert T. Michael, 1995. Measuring poverty: a new approach, Washington, DC, National Academy Press. 
De Vos, Klaas, and Thesia I. Garner, 1991, "An evaluation of subjective poverty definitions: comparing results from the U.S. and the Netherlands," Review of Income and Wealth, 37:3, 267-85.

Deaton, Angus, 2001, “Counting the world's poor: problems and possible solutions,” World Bank research Observer, 16:2, 125-47.

Deaton, Angus, 2005, "Measuring poverty in a growing world (or measuring growth in a poor world), Review of Economics and Statistics, 87:1, 1-19.

Deaton, Angus, 2008, "Income, health, and wellbeing around the world: evidence from the Gallup World Poll,” Journal of Economic Perspectives, 22:2, 53-72.

Deaton, Angus, and Olivier Dupriez, 2009, "Purchasing power parity exchange rates for the global poor,” Research Program in Development Studies, Princeton. http://www.princeton.edu/ deaton/downloads/Purchasing_power_parity_exchange_rates_f or_global_poor_Nov11.pdf

Deaton, Angus, and Jean Drèze, 2009, "Food and nutrition in India: facts and interpretations,” Economic and Political Weekly, 44:7, 42-65.

Deaton, Angus, and Alan Heston, 2010, “Understanding PPPs and PPP-based national accounts,” American Economic Journal: Macroeconomics, forthcoming.

Diewert, W. Erwin, 1976, “Exact and superlative index numbers,” Journal of Econometrics, 4(2), 115-45.

Diewert, W. Erwin, 2008, “New methodology for linking the regions,” Dept. of Economics, University of British Columbia (September.) Available at http://www.econ.ubc.ca/diewert/dp0807.pdf

Dowrick, Steve, and Muhammad Akmal, 2005, "Contradictory trends in global income inequality: a tale of two biases,” Review of Income and Wealth, 51:2, 201-29.

Easterlin, Richard, 1974, "Does economic growth improve the human lot? Some empirical evidence,” in Paul A. David and Melivin W. Reder, eds., Nations and households in economic growth: essays in honor of Moses Abramovitz, New York. Academic Press.

Fisher, Franklin, and Karl Shell, 1971, "Taste and quality change in the pure theory of the true cost-of-living index,” in Zvi Griliches, ed., Price indexes and quality change, Cambridge. Harvard University Press.

Gini, Corrado, 1924, "Quelques considerations au sujet de la construction des nombres indices des prix et des questions analogues,” Metron, 4, 3-162. 
Goedhart, Theo, Victor Halberstadt, Arie Kapteyn, and Bernard van Praag, 1977, "The poverty line: concept and measurement,” Journal of Human Resources, 12:4, 503-20.

Himanshu, 2008, "What are these new poverty estimates and what do they imply?" Economic and Political Weekly, October 25, 38-43.

Jodha, N.S., 1988, “Poverty debate in India: a minority view," Economic and Political Weekly, 23:45-7, 2421-25, 2427-28.

Kuznets, Simon, 1955, "Economic growth and income inequality,” American Economic Review, 45:1, 1-28.

Milanovic, Branko, 2009, “Global inequality recalculated: the effect of new 2005 PPP estimates on global inequality,” World Bank Policy Research Working Paper No. 5061. (Sep.) http://papers.ssrn.com/sol3/papers.cfm?abstract_id=1478814 (Downloaded, Jan. 10, 2010.)

Nagel, Thomas, 2005, “The problem of global justice,” Philosophy and Public Affairs, 33:2, $113-47$.

Pinkovskiy, Maxim, and Xavier Sala-i-Martin, 2009, "Parametric distributions of the world distribution of income,” NBER Working Paper No. 15433, Cambridge, MA. NBER (Oct.)

Pogge, Thomas W., 2002, World poverty and human rights: cosmopolitan responsibilities and reforms, Cambridge Ma. Polity Press.

Pradhan, Menno, and Martin Ravallion, 2000, "Measuring poverty using qualitative perceptions of consumption adequacy," Review of Economics and Statistics, 82:3, 462-71.

Ravallion, Martin, 1992, Poverty comparisons, Living Standards Measurement Study Working Paper No. 88, Washington, DC. World Bank. (Feb.)

Ravallion, Martin, Shaohua Chen, and Prem Sangraula, 2009, "Dollar a day revisited,” World Bank Economic Review, 23:2, 163-84.

Ravallion, Martin, Gaurav Datt and Dominique van de Walle, 1991, "Quantifying absolute poverty in the developing world,” Review of Income and Wealth, 37:4, 345-61.

Ravallion, Martin, and Shaohua Chen, 1997, "What can new survey data tell us about recent changes in distribution and poverty?” World Bank Economic Review, 11:2, 357-82.

Rawls, John, 1999, The law of peoples, Cambridge, MA. Harvard University Press.

Sen, Amartya K., 1973, On economic inequality, Oxford. Clarendon Press.

Sen, Amartya, K, 1976, “Real national income,” Review of Economic Studies, 43:1, 19-39. 
Singer, Peter, 2002, One world: the ethics of globalization, New Haven, CT. Yale University Press.

Stevenson, Betsey, and Justin Wolfers, 2008, "Economic growth and subjective wellbeing: reassessing the Easterlin paradox,” Brookings Papers on Economic Activity, (Spring) 1102.

Stone, J. Richard N., 1949, in Milton Gilbert, Colin Clark, Richard Stone, François Perroux, et al., "The measurement of national wealth: discussion," Econometrica, 17, Supplement, Report of the Washington Meeting, 255-72.

Sun, Changqing and Eric Swanson, 2009, “Estimation of PPPs for non-benchmark economies for the 2005 ICP round,” ICP Bulletin, 6:1, 20-3.

Van Praag, Bernard M. S., 1968, Individual welfare functions and consumer behavior, Amsterdam. North-Holland.

Wenar, Leif, 2006, “Why Rawls is not a cosmopolitan egalitarian,” in Rex Martin and David Reidy, eds., Rawls’ Law of Peoples: a realistic Utopia? Oxford. Blackwell, 2006.

World Bank, 1990, World Development Report 1990, Poverty. Washington DC. Oxford

World Bank, 2008a, Global purchasing power parities and real expenditures: 2005 international comparison program, Washington, DC. The World Bank.

World Bank, 2008b, Poverty data: a supplement to the World Development Indicators 2008, Washington, DC. The World Bank. 


\begin{tabular}{|c|c|c|c|c|c|c|}
\hline & \multicolumn{3}{|c|}{ Time series } & \multicolumn{3}{|c|}{ Alternate estimates for 1993} \\
\hline & 1981 & 1993 & 2005 & 1993 & 1993 & 1993 \\
\hline Poverty line & $\$ 1.25$ & $\$ 1.25$ & $\$ 1.25$ & $\$ 1.01$ & $\$ 1.08$ & $\$ 1.25$ \\
\hline PPP date & 2005 & 2005 & 2005 & 1985 & 1993 & 2005 \\
\hline East Asia \& Pacific & 77.7 & 50.8 & 16.8 & 26.0 & 25.2 & 50.8 \\
\hline Europe \& Central Asia & 1.7 & 4.3 & 3.7 & 3.5 & 3.5 & 4.3 \\
\hline Latin America \& Caribbean & 12.9 & 10.1 & 8.2 & 23.5 & 15.3 & 10.1 \\
\hline Middle East \& n. Africa & 7.9 & 4.1 & 3.6 & 4.1 & 1.9 & 4.1 \\
\hline South Asia & 59.4 & 46.9 & 40.3 & 43.1 & 42.4 & 46.9 \\
\hline Sub-Saharan Africa & 53.4 & 56.9 & 50.9 & 39.1 & 49.7 & 56.9 \\
\hline Total percentage in poverty & 51.9 & 39.2 & 25.2 & 29.4 & 28.2 & 39.2 \\
\hline Total millions in poverty & 1,900 & 1,799 & 1,374 & 1,350 & 1,304 & 1,799 \\
\hline
\end{tabular}

Sources: Columns (1) through (3) and column (6) from World Bank (2008b, Table 3). Column (4) from Martin Ravallion and Shaohua Chen (1997, Table 5). Column (5) from Chen and Ravallion (2000, Table 2).

Notes: Poverty line is the global poverty line expressed in year $\mathrm{X}$ international dollars, where $\mathrm{X}$ is the PPP date. Apart from the poverty line, the PPP date, and the total millions in poverty, all numbers are percentages and are estimates of the fraction of the populations of the covered (developing) countries that are in poverty in each year. All numbers are estimated from household survey data.

Table 2: Root mean square distance of prices of consumption over 62 countries

\begin{tabular}{lllll}
\hline & ICP & NAS weights & Survey weights & Poverty weights \\
\cline { 2 - 4 } & 0 & 0.156 & 0.150 & 0.158 \\
ICP & & 0 & 0.065 & 0.104 \\
NAS weights & & 0 & 0.057 \\
Survey weights & & & 0 \\
Poverty weights & & & \\
\hline
\end{tabular}

Notes: The price of consumption is as defined in Table 2. The numbers shown are the root mean squared difference between the consumption price indexes taken over 62 developing countries. See Table 3 for definitions of the indexes.

Source: Deaton and Dupriez (2009), Tables 2 and 8. 
Table 3: Price of consumption in countries with largest numbers of poor people, 2005

\begin{tabular}{llllll|}
\hline & & \multicolumn{3}{l}{ Basis for PPP calculation } & \\
\cline { 3 - 5 } & $\begin{array}{l}\text { \# poor } \\
\text { (millions) }\end{array}$ & ICP & NAS & Surveys & $\begin{array}{c}\text { Poverty } \\
\text { weights }\end{array}$ \\
\cline { 3 - 5 } India & 456 & & & & 1.000 \\
China & 212 & 1.000 & 1.000 & 1.000 & 1.000 \\
Bangladesh & 77 & 1.411 & 1.404 & 1.354 & 1.325 \\
Indonesia & 47 & 1.120 & 1.091 & 1.077 & 1.040 \\
Pakistan & 35 & 1.221 & 1.185 & 1.184 & 1.160 \\
& & 0.984 & 1.038 & 1.071 & 1.080 \\
Nigeria & 88 & 1.692 & 1.836 & 1.826 & 1.884 \\
Congo, Dem Rep. & 35 & 1.886 & 1.975 & 1.989 & 1.964 \\
Tanzania & 32 & 1.218 & 1.304 & 1.267 & 1.237 \\
Ethiopia & 29 & 0.897 & 1.068 & 1.039 & 1.002 \\
\hline
\end{tabular}

Notes: The number of poor people in 2005 is calculated using the consumption PPPs from the ICP as published, and the Bank's global poverty line of $\$ 1.25$ a day. The countries shown are those with the largest numbers of poor people. The four other columns show the price of consumption in each country, the ratio of the consumption PPP to the average 2005 official exchange rate, with India as base. Numbers greater than 1 indicate that local prices are higher than Indian prices converted at the official exchange rate. The ICP column is based on the consumption PPP for individual household consumption in the ICP. The NAS column uses PPPs recalculated using ICP prices and ICP expenditure weights: there are recalculated using 62 developing countries only using a uniform Fisher GEKS procedure without imposing regional fixity. The "surveys" column replicates this calculation with survey expenditure weights in place of national accounts weights, and the "poverty weights" uses a poverty weighted PPP with expenditure weights around a global poverty line that is the poverty-weighted average of the international rupee value of 50 national poverty lines.

Source: Deaton and Dupriez (2009), Tables 17, 1, and 5.

Table 4: Ratio of parity for actual and imputed rental to parity for household individual consumption, selected countries 2005

\begin{tabular}{llll}
\hline Country & Ratio of parities & Country & Ratio of parities \\
\hline Chad & 0.176 & Niger & 0.318 \\
Ethiopia & 0.520 & Rwanda & 0.846 \\
Gambia & 0.110 & Sierra Leone & 0.184 \\
Ghana & 0.048 & Tanzania & 0.607 \\
Guinea-Bissau & 0.259 & Tajikistan & 0.119 \\
Malawi & 0.150 & Uganda & 0.581 \\
Mali & 0.525 & & \\
Mozambique & 0.215 & China & 0.832 \\
Nepal & 0.904 & India & 0.602 \\
\hline
\end{tabular}

Notes: The numbers shown are the ratios of the parity for actual and imputed rents to the parity for household individual consumption. China and India are shown for comparison. 
Table 5: Global poverty lines in world rupees per person per day

\begin{tabular}{|c|c|c|c|c|}
\hline & \multicolumn{4}{|c|}{$\begin{array}{l}\text { P3 Indexes: Plutocratic Purchasing Power Parities } \\
\text { using unweighted mean of } 14 \text { poorest countries as international poverty line }\end{array}$} \\
\hline Source for weights & ICP: NAS & NAS 105 & NAS 102 & Surveys \\
\hline ICP/Chen-Ravallion & 19.49 & -- & -- & -- \\
\hline \multirow[t]{2}{*}{ Fisher } & -- & 18.98 & 18.05 & 17.81 \\
\hline & \multicolumn{4}{|c|}{ P4 Indexes: Poverty weighted Purchasing Power Parities } \\
\hline Poverty line selection & $\begin{array}{l}\text { Unweighted mean of } \\
14\end{array}$ & & Weighted me & \\
\hline Fisher & 18.31 & & 16.04 & \\
\hline
\end{tabular}

Notes: The first number in the top panel, 19.49, is the Bank's global poverty line of $\$ 38$ a month ( $\$ 1.25$ a day) converted into Indian rupees using the conversion factor of 15.602 which is the PPP for household individual consumption for India relative to the US taken from the final report. If we calculate this number directly, using the poverty lines of the 15 poorest countries, converted to international dollars using their PPPs for household individual consumption, and taking an unweighted average, we get 1.24 international dollars or 19.34 world rupees. If we exclude Guinea-Bissau from the 15 poorest countries, so as to make the calculations comparable with our own calculations for which we do not have a survey for Guinea-Bissau, we get 1.22 international dollars or 19.06 world rupees. The column headed NAS 105 shows the simple average of poverty lines converted at the PPP for household individual consumption on a NAS basis directly calculated in one step using GEKS-Fisher, and using all 105 basic heads. The column headed NAS 102 is the same as NAS 105, but with three basic heads dropped: FISIM, prostitution, and actual and imputed household rents. The column labeled surveys also uses 102 basic heads, and also uses an aggregate PPP, but uses surveys to estimate aggregate expenditures instead of the national accounts. The bottom panel shows three sets of poverty lines that use P4s (bandwidth 0.5 ) for conversion to international rupees; in all cases, the global poverty line is calculated simultaneously with the P4s. In the first column, the global line is calculated as the simple average of the 14 poorest country poverty lines at the final estimates of the P4s. The second column uses poverty lines from 50 countries, and weighted by the number of poor in each country at the final global poverty line.

Source: Adapted from Deaton and Dupriez (2009, Table 11.) 
Table 6: Alternative global poverty counts and poverty lines

\begin{tabular}{lllllll}
\hline $\begin{array}{l}\text { \# of country } \\
\text { lines }\end{array}$ & $\begin{array}{l}\text { Averaging } \\
\text { Method }\end{array}$ & $\begin{array}{l}\text { PPP } \\
\text { weighting } \\
\text { type }\end{array}$ & Formula & $\begin{array}{c}\text { Line in \$ or } \\
\text { rupees }\end{array}$ & $\begin{array}{l}\text { Line in } \\
\text { "star" \$ }\end{array}$ & $\begin{array}{l}\text { \# of poor, } \\
\text { millions }\end{array}$ \\
\hline 15 & Simple & P3 & ICP & $\$ 1.25$ & -- & 1,319 \\
14 & simple & P4 & GEKS & R18.97 & 1.064 & 1,164 \\
50 & poverty & P4 & GEKS & R16.04 & 0.922 & 874 \\
\hline
\end{tabular}

Notes: The first line shows the official procedure. The global poverty line is a simple average of national poverty lines of 15 countries, using a plutocratic PPP for consumption, and incorporating the various aggregation procedures employed in the ICP. The resulting line is $\$ 1.25$ per person per day in 2005 international dollars, and the resulting poverty count is 1,319 million. (This number differs from the estimate in Table 1, taken from World Bank, 2008, because of later revisions.) The second row uses 14 of the 15 countries for which there are household surveys, and calculates poverty weighted PPPs, again with a simple average of the 14 national lines. The P4s are calculated using (Gini) EKS-Fisher aggregation, and give a global line of 18.97 international rupees per day. The final line uses 50 national lines, which are poverty-count weighted. The conversion of the P4 lines to \$ is carried out using a "star" PPP calculation that uses an average of $\$$ to international rupee conversions over 62 poor countries, see text for details.

Source: Extracted from Deaton and Dupriez (2009, Tables 11, 14, and 15). 
Table 7: Most influential basic headings in pairwise Törnqvist indexes: ring African countries versus UK

\begin{tabular}{llll}
$\begin{array}{l}\text { Budget share in } \\
\text { country }\end{array}$ & $\begin{array}{l}\text { Budget share in } \\
\text { UK }\end{array}$ & $\begin{array}{l}\text { price ratio } \\
\text { relative to UK } \\
\text { relative to } \\
\text { average }\end{array}$ & $\begin{array}{l}\gamma \text { influence } \\
\text { measure } \\
\text { (percent) }\end{array}$ \\
\hline
\end{tabular}

\begin{tabular}{|c|c|c|c|c|}
\hline \multicolumn{5}{|l|}{ Cameroon } \\
\hline Passenger air travel & 0.0112 & 0.0229 & 11.6 & 4.17 \\
\hline Other cereals & 0.0578 & 0.0049 & 3.06 & 3.51 \\
\hline Motor cars & 0.0052 & 0.0671 & 2.19 & 2.83 \\
\hline Catering services & 0.0699 & 0.1420 & 0.82 & -2.07 \\
\hline Domestic services & 0.0136 & 0.0028 & 0.05 & -2.46 \\
\hline Potatoes & 0.1492 & 0.0022 & 0.41 & -6.67 \\
\hline \multicolumn{5}{|l|}{ Kenya } \\
\hline Motor cars & 0.0140 & 0.0675 & 2.22 & 3.38 \\
\hline Telephone and telefax & 0.0391 & 0.0276 & 2.52 & 3.06 \\
\hline Other cereals & 0.0959 & 0.0050 & 1.72 & 2.58 \\
\hline Hairdressing & 0.0109 & 0.0093 & 0.22 & -1.53 \\
\hline Tobacco & 0.0120 & 0.0292 & 0.25 & -2.94 \\
\hline Vegetables & 0.0952 & 0.0109 & 0.44 & -4.10 \\
\hline \multicolumn{5}{|l|}{ Senegal } \\
\hline Motor cars & 0.0129 & 0.0663 & 1.95 & 2.61 \\
\hline Telephone and telefax & 0.0629 & 0.0271 & 1.60 & 2.12 \\
\hline Air travel & 0.0055 & 0.0226 & 3.10 & 1.58 \\
\hline Fish & 0.0376 & 0.0028 & 0.39 & -1.92 \\
\hline Domestic service & 0.0086 & 0.0028 & 0.03 & -2.08 \\
\hline Tobacco & 0.0234 & 0.0289 & 0.23 & -3.79 \\
\hline \multicolumn{5}{|l|}{ Zambia } \\
\hline Passenger air travel & 0.0116 & 0.0226 & 11.3 & 4.33 \\
\hline Motor cars & 0.0039 & 0.0663 & 2.35 & 3.35 \\
\hline Telephone and telefax & 00082 & 0.0271 & 3.17 & 2.18 \\
\hline Cultural services & 0.0061 & 0.0402 & 0.38 & -2.42 \\
\hline Catering services & 0.0000 & 0.1403 & 0.70 & -2.81 \\
\hline Electricity & 0.1883 & 0.0175 & 0.46 & -7.08 \\
\hline
\end{tabular}

Notes: The base country is the UK. The budget shares refer to the share in all ring expenditures of each basic heading including only expenditures for which the price of the basic head is available in both countries. (That this set changes across pairs explains the (small) differences in the budget shares in the UK for the same category when comparing different countries.) The budget shares are also larger than the budget share in all consumption expenditure, e.g. the share of passenger air travel in total consumption in Cameroon is 0.0089 not 0.112 ) The price ratio relative to UK relative to average is the ratio of the price of the basic heading in local currency in $c$ to its price in the UK in $£$ divided by the overall Törnqvist pairwise PPP from the ring. Note that the overall pairwise PPPs are not the same as the PPPs in Table 7. 
Table 8: Most influential basic headings in pairwise Törnqvist indexes: Africa and Asia versus OECD

\begin{tabular}{|c|c|c|c|c|}
\hline & $\begin{array}{l}\text { Budget share in } \\
\text { region }\end{array}$ & $\begin{array}{l}\text { Budget share in } \\
\text { OECD }\end{array}$ & $\begin{array}{l}\text { price ratio } \\
\text { relative to } \\
\text { OECD relative } \\
\text { to average }\end{array}$ & $\begin{array}{l}\gamma \text { influence } \\
\text { measure } \\
\text { (percent) }\end{array}$ \\
\hline \multicolumn{5}{|l|}{ Africa } \\
\hline Pharmaceutical products & 0.0062 & 0.0313 & 4.25 & 2.71 \\
\hline Motor cars & 0.0090 & 0.0344 & 1.70 & 1.15 \\
\hline Telephone and telefax & 0.0080 & 0.0202 & 1.99 & 0.97 \\
\hline Recreational and sports & 0.0021 & 0.0142 & 2.53 & 0.76 \\
\hline Furniture and furnishings & 0.0063 & 0.0125 & 2.04 & 0.67 \\
\hline Tobacco & 0.0164 & 0.0161 & 0.55 & -0.99 \\
\hline Road travel & 0.0233 & 0.0114 & 0.53 & -1.09 \\
\hline Paramedical services & 0.0117 & 0.0194 & 0.44 & -1.29 \\
\hline Dental services & 0.0291 & 0.0207 & 0.33 & -2.74 \\
\hline Rental of housing & 0.1417 & 0.1589 & 0.75 & -4.24 \\
\hline \multicolumn{5}{|l|}{ Asia-Pacific } \\
\hline Rental of housing & 0.1005 & 0.1589 & 1.58 & 5.90 \\
\hline Pharmaceutical products & 0.0504 & 0.0313 & 1.69 & 2.15 \\
\hline Gas & 0.0139 & 0.0088 & 4.86 & 1.79 \\
\hline Telephone and telefax & 0.0374 & 0.0202 & 1.45 & 1.07 \\
\hline Motor cars & 0.0035 & 0.0344 & 1.61 & 0.90 \\
\hline Paramedical services & 0.0108 & 0.0194 & 0.36 & -1.53 \\
\hline Dental services & 0.0135 & 0.0207 & 0.38 & -1.65 \\
\hline Social protection & 0.0434 & 0.0359 & 0.66 & -1.67 \\
\hline Road transport & 0.0489 & 0.0114 & 0.56 & -1.73 \\
\hline Hospital services & 0.0341 & 0.0495 & 0.57 & -2.37 \\
\hline
\end{tabular}

Notes: The base country is the UK. The budget shares refer to the share in all ring expenditures of each basic heading. The price ratio relative to UK relative to average is the ratio of the price of the basic heading in local currency in $c$ to its price in the UK in $£$ divided by the overall Törnqvist pairwise PPP from the ring. Note that the overall pairwise PPPs are not the same as the PPPs in Table 7. 
Table 9: Correlations between log GDP per capita and well-being measures from the Gallup World Poll

\begin{tabular}{|c|c|c|c|c|c|c|}
\hline Levels & & 2006 & & 2007 & & 2008 \\
\hline Ladder & 0.820 & & 0.812 & & 0.831 & \\
\hline No money for food & -0.800 & & -0.762 & & -0.760 & \\
\hline Living standard poor & -0.631 & & -0.576 & & -0.642 & \\
\hline Difficult or v. difficult to get by & -- & & -0.654 & & -0.768 & \\
\hline Very difficult to get by & -- & & -0.632 & & -0.730 & \\
\hline Changes & & $2007-2006$ & & 2008-2007 & & $2008-2006$ \\
\hline Ladder & 0.058 & & -0.044 & & 0.049 & \\
\hline No money for food & 0.239 & & -0.001 & & 0.107 & \\
\hline Living standard poor & 0.046 & & 0.004 & & 0.004 & \\
\hline Difficult or v. difficult to get by & -- & & -0.068 & & -- & \\
\hline Very difficult to get by & -- & & -0.031 & & -- & \\
\hline
\end{tabular}


Table 10: Global and regional tracking of living standards, 2006 to 2009

(Average scores and increments over base year for ladder, percentages and percentage point change over base year other measures)

\begin{tabular}{|c|c|c|c|c|}
\hline & $\begin{array}{l}2006 \\
\text { (base) }\end{array}$ & 2007 & 2008 & 2009 \\
\hline \multicolumn{5}{|l|}{ World } \\
\hline Ladder & 5.33 & 5.42 & 5.36 & 5.43 \\
\hline No money for food & 32.5 & 26.3 & 24.9 & 29.0 \\
\hline Living standards poor & 37.9 & 36.4 & 38.2 & 38.6 \\
\hline In difficulty & -- & 39.3 & 40.5 & 43.1 \\
\hline \multicolumn{5}{|l|}{ Sub-Saharan Africa } \\
\hline Ladder & 4.25 & 4.60 & 4.56 & 4.57 \\
\hline No money for food & 55.0 & 50.8 & 56.3 & 56.8 \\
\hline Living standards poor & 61.4 & 58.8 & 62.3 & 62.6 \\
\hline In difficulty & -- & 58.3 & 60.3 & 67.6 \\
\hline \multicolumn{5}{|l|}{ South Asia } \\
\hline Ladder & 5.18 & 5.02 & 5.01 & 5.29 \\
\hline No money for food & 33.3 & 26.0 & 23.6 & 28.4 \\
\hline Living standards poor & 36.0 & 35.1 & 38.6 & 43.0 \\
\hline In difficulty & -- & 54.7 & 55.4 & 58.7 \\
\hline
\end{tabular}

Notes: Except for "In difficulty" for which the base year is 2007, the population weighted global average for 2006 is given in the first column. For "in difficulty" the second column shows the global average for 2007. All columns are the predicted values of a population weighted factor regression in which the relevant measure is regressed on a set of year and country dummies. The World regressions are run for all countries pooled, while the regional regressions pool data over all countries in the region. The ladder on a scale from 0 to 10. The other measures are changes in percentages. 


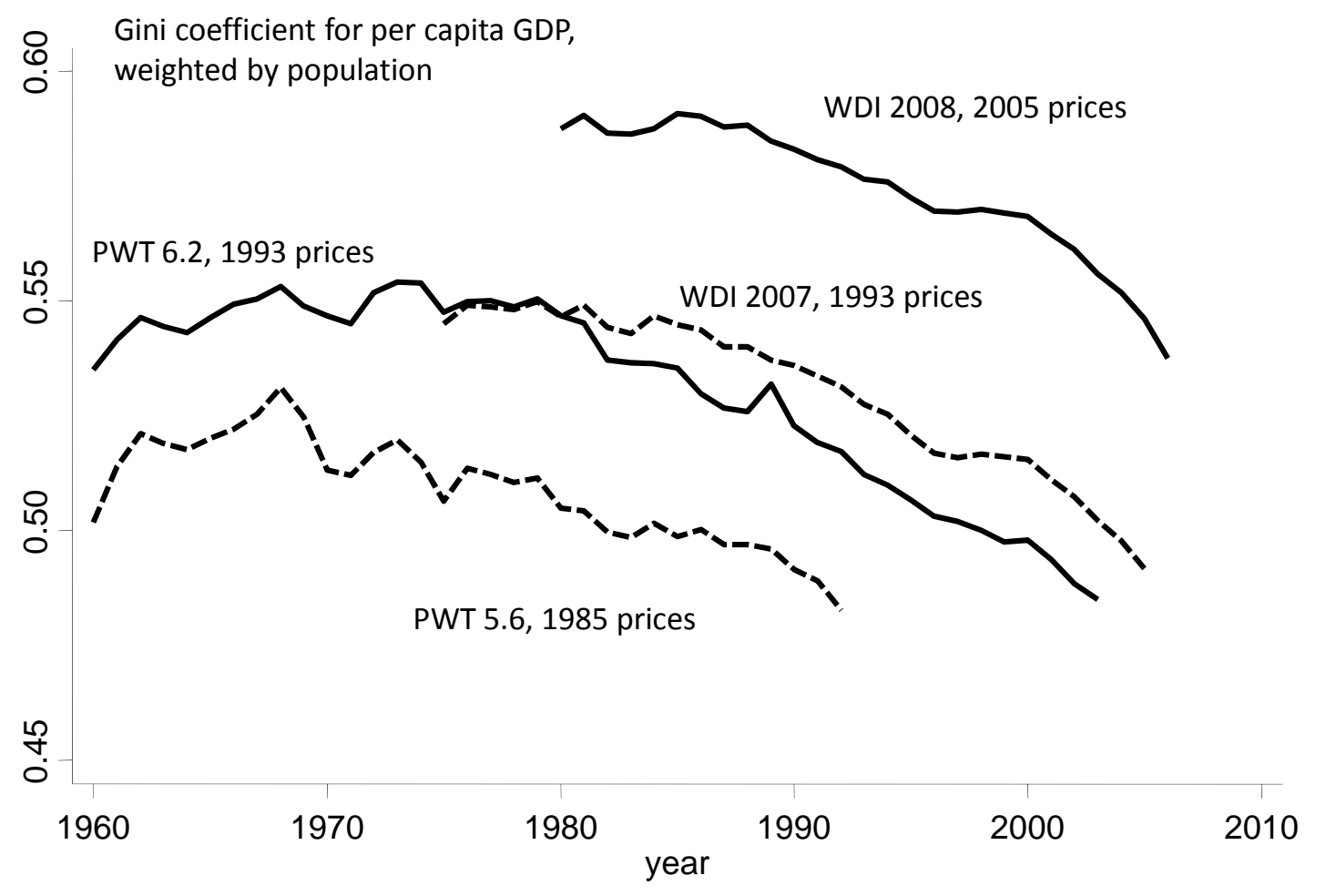

Figure 1: Gini coefficients for population weighted national incomes 


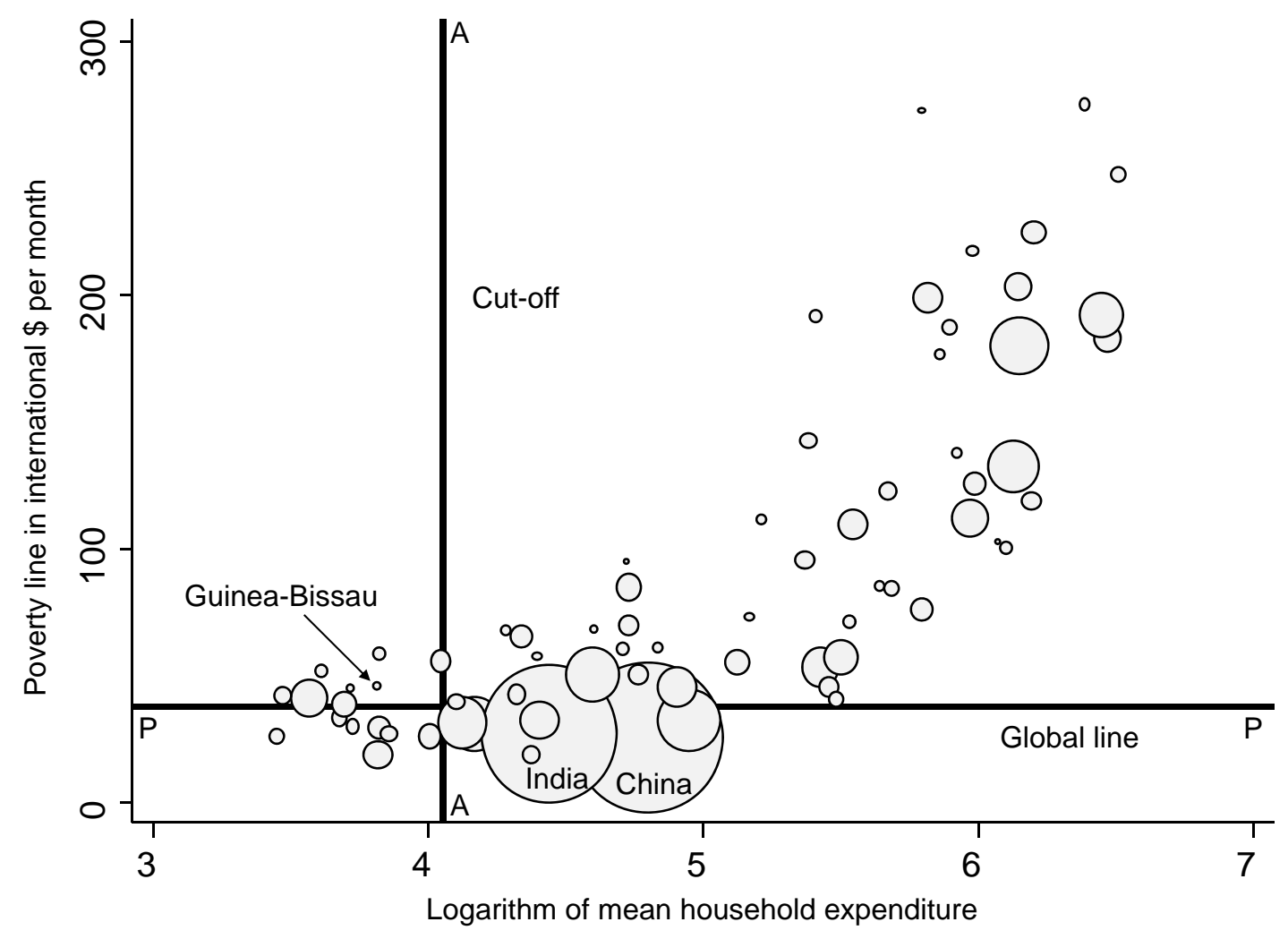

Figure 2: The construction of the global poverty line 


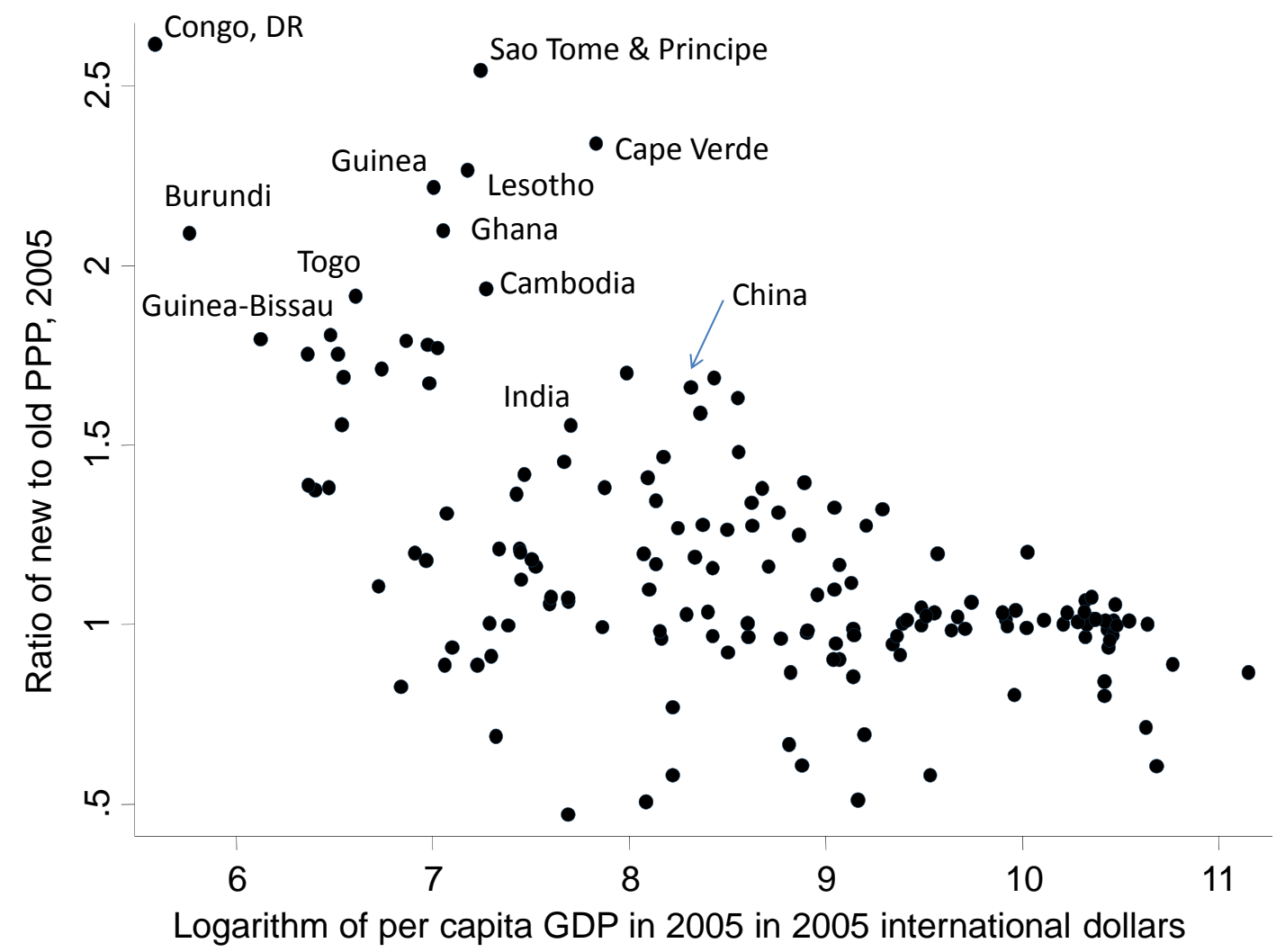

Figure 3: Ratios of old to new PPPs for GDP as a function of per capita GDP 


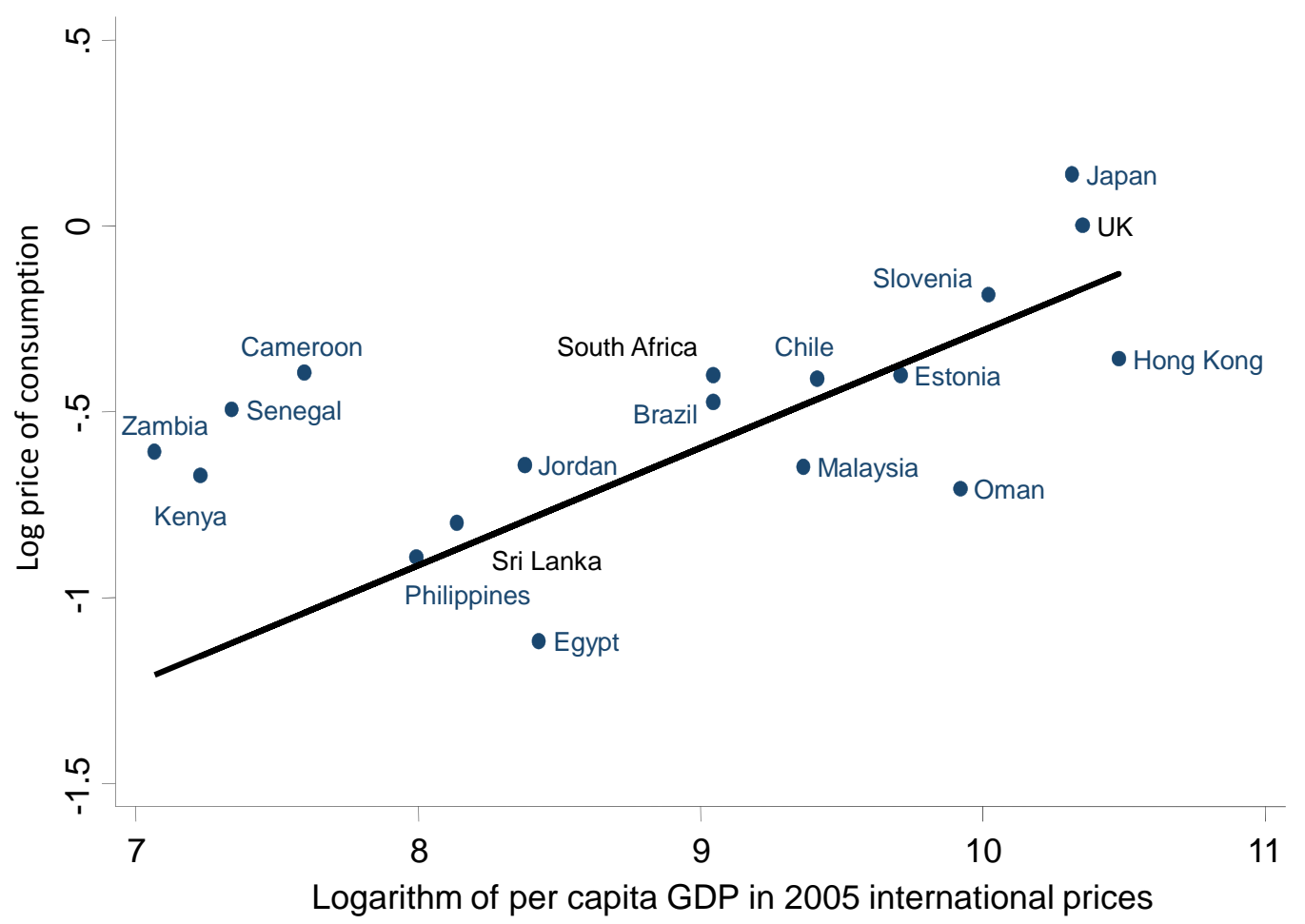

Figure 4: Prices of consumption relative to GDP per capita, 18 ring countries 


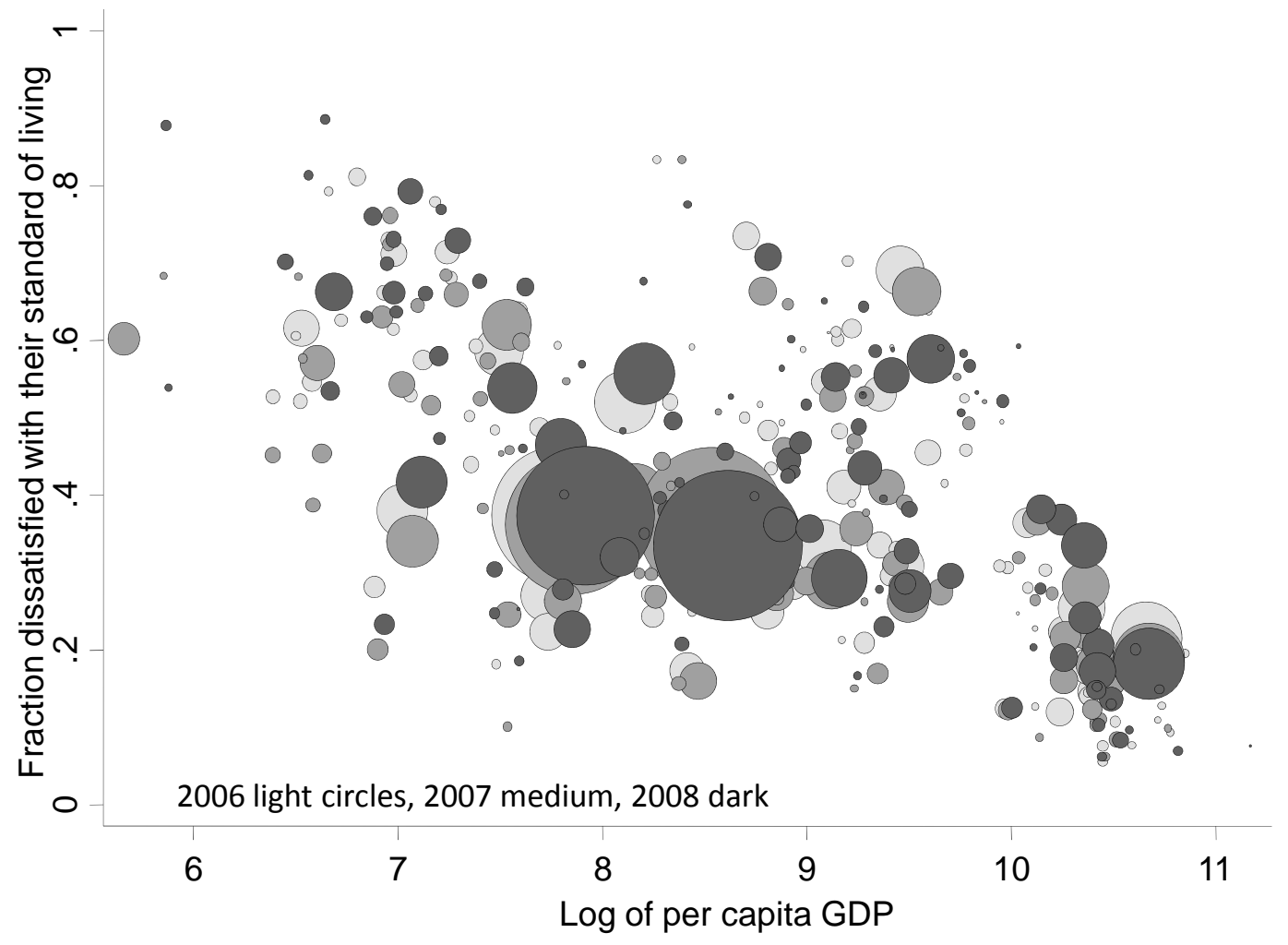

Figure 5: Fractions of people that they are dissatisfied with their standard of living 